\title{
Consciousness Mesh Theory and Its Application to Food Related Human Behavior
}

\author{
Jae-Kun Chun1, Wan Il Cho'2, Seokwon Lim³ \\ ${ }^{1}$ Department of Food and Animal Biotechnology, Seoul National University, Seoul, Republic of Korea \\ ${ }^{2}$ Sensometrics Inc., Seoul, Republic of Korea \\ ${ }^{3}$ Department of Food Science and Technology, Hoseo University, Asan-si, Republic of Korea \\ Email: chunjae@snu.ac.kr
}

How to cite this paper: Chun, J.-K., Cho, W. I., \& Lim, S. (2017). Consciousness Mesh Theory and Its Application to Food Related Human Behavior. Psychology, 8, 168-205.

http://dx.doi.org/10.4236/psych.2017.81011

Received: November 23, 2016

Accepted: January 17, 2017

Published: January 20, 2017

Copyright $\odot 2017$ by authors and Scientific Research Publishing Inc. This work is licensed under the Creative Commons Attribution International License (CC BY 4.0).

http://creativecommons.org/licenses/by/4.0/

c) (i) Open Access

\begin{abstract}
A hypothetical consciousness mesh theory (CM theory) composed of multiple consciousness mesh layer (mCML) is developed on the basis of scientific evidences. Various virtual terms were defined to visualize the consciousness realities such as consciousness fiber, aggregate and aggregate cluster, which develop to the formation of self, life cycle and experiences. The pathway dependent consciousness process with 3-way branching perception logic was described. The CM theory was applied to food related conscious and non-conscious issues such as food acceptance, consumption, virtual food and cognitive sensory evaluation (CSE) method. Using the CSE method food consumer's response reflecting unconscious mind set can be visualized as a barcode and table-set patterns for food item. Based on CML process logic, food acceptance model was developed and practiced for several food items and food related behaviors. Effect of pregnancy to food related response was also studied focusing on morning sickness of pregnant women group, and a remarkable difference between pregnant experience and non-pregnant experience women group in their responses.
\end{abstract}

\section{Keywords}

Consciousness Mesh, 3-Way Branching Transfer, Sensory Barcode, Cognitive Sensory, Food Acceptance, Virtual Food, Pregnancy

\section{Introduction}

Food scientists understand that the individuals' state of mind affects food and food-related behaviors, and that the self has an immense influence on food life including choice, purchase, and consumption of food. In this line, psychological approach is increasingly importance of food science, particularly in the sensorial 
and industrial fields because material and mind are inseparable nature in many aspects.

First, psychologists have a better understanding of the mind than food scientists, but they know less about material field, and the mind-body problem is an equally important issue in all academic fields (Dy, 2001). However, consciousness is defined differently in various fields: the mind in general, awareness in the medical sector, spirit in religion, and so on. The awareness and it is divided into self-awareness, higher-order awareness, and medical awareness. (Hohwy, 2009; Massimini et al., 2005; Owen et al., 2006; Ferrarelli et al., 2010). Many scientists claim that the mind is brain activity that gives rise to consciousness (Shepherd, 1994). Consciousness is also considered as experience, or sometimes called content-consciousness (Hohwy, 2009).

So far, the known features of consciousness are that it is invisible, non-material, controls animals, has a non-locality role in every living creature, and is empty, among other qualities like eternality and infinity.

As we try to consider food resources from a consciousness perspective, we face the difficulty of how to link awareness of plants to a higher level of human consciousness and unconsciousness. Prior to discussing the involvement of unconscious processes in the experience of food taste, it is also necessary to provide a brief review of the terminology associated with this phenomenon due to big differences between medical, cognitive, psychological, and religious sectors regarding its definition and effects.

This definition may also be confused with the psychoanalytic notion of unconscious cognitive processes (e.g., implicit cognition) that occur outside of awareness (Epstein, 1994; Kiefer \& Brendel, 2006). Food digestion is also processed unconsciously. In psychology, consciousness is considered to be the means by which we think, decide, and act. Bargh et al. (1996) believed that consciousness initiates a multi-step process by which the new slow behaviors we seek to adopt are repeated and reinforced to such an extent that these behaviors eventually become more rapid and automatic until they occur automatically without any conscious effort. Hence, unconsciousness achieved in this way is understood as effective with regard to judging and decision making (Williams et al., 2009).

The most influential modern physical theories of consciousness are based on psychology and neuroscience. Theories proposed by neuroscientists such as Edelman (1992) and Damasio (1999), and by philosophers such as Dennette (1991) seek to explain consciousness in terms of neural events occurring within the brain. Many other neuroscientists, such as Koch (2004) claimed that human body is controlled by the brain composed of a complex, Neuronal Correlates of Consciousness (NCC) may be linked with consciousness) (Koch \& Tononi 2008).

These efforts, however, are almost based on the hardware connectivity of neurons neglecting software nature of consciousness. Hawkins (2005) developed brain theory based on hierarchical structure found in the structure of neocortex 
where high level knowledge of sensory data is stored. In short, brain is functioning as a hierarchical consciousness structure. Wilson (1977) explains each of the eight brains, circuit theory, and it is comparable to the hierarchical consciousness theory developed by Buddhist concept of Indra's net from the Avatamsaka Sutra (Keown, 2003). Hierarchical temporal memory (HTM) is a machine learning model developed by Hawkins and Sandra (2005). Author has set out the development of a fundamental consciousness mesh theory based on scientific evidences, although issues with debate on scientific fields such as quantum physics, astrophysics, neuroscience, biology, and cognitive sciences.

\section{Hypothesis of Consciousness Mesh Theory}

\subsection{Premise for Consciousness Mesh Theory}

Considering the above mentioned nature of the mind or consciousness, author summarized the notions similar to consciousness found in several scientific fields as the followings:

-The visible material world is fundamentally empty and inter-linked in terms of the coherent; and the role of the observer is accepted as important (Quantum physics, (Pais, 1991; Heisenberg, 1927; Gasiorowicz, 1974; Goswami, 1993)).

-Empty space of the universe is filled with invisible dark matter and dark energy as the basic framework (Astrophysics, (Trimble, 1987; Hinshaw, 2010; Copi et al., 1995; Bergstrom, 2000; Bertone et al., 2005; Peebles \& Ratra, 2003; Jarosik et al., 2010)).

-Living material is composed of electrons and protons, and any compound is constructed by the options of binding bonds among atoms (Chemistry).

-Living beings with different sizes and intelligent have been developed from a cell that has a membrane to protect itself from the external world. They have a hierarchical information processing system with chemical and genetic signals for the self and similarity among species exist in terms of genetic code (Biology, (Koch, 2004; Paradiso, 2002)). Visible and sensible material world may be a representative phenomenon of invisible consciousness. The conscious world is filled up by consciousness itself, whatever the structure is or whether the universe originally emerged from consciousness.

\subsection{Classification of Consciousness with Unified Scale of Layer}

In order to simplify the complicated world of consciousness the analogy of a light prism may be helpful. Before sunlight passes through a prism, light is colorless or invisible, but after passing through the prism, seven colors or rainbow bands appear, each visible color having different band widths. Scientists have agreed to put various electromagnetic waves into a single unified scale of wave length, and we can relate wave energies to wave length in terms of $\mathrm{Hz}$ units. The classification of sunlight would be impossible without interfacing substance and quartz prism; similarly, our original consciousness can be diversified into various states of consciousness by interfacing the biological body or brain of individual beings. 
In this perspective consciousness and unconsciousness should be placed on the same continuum within boundaries based on their functions and tasks as like the different lights arrayed in single magnetic wave spectrum. In a similar way, unconsciousness dominates consciousness and occupies a higher position in terms of the hierarchical structure of the mind in a consciousness spectrum. Author attempted to categorize consciousness into levels or layers in accordance with intelligent level of beings as illustrated in Figure 1.

Although single cell, plant and insect are different in terms of biological level, they have similar genetic codes maps with which the more precise identifications and classification is possible as well acknowledged in many life science fields such as microbiology, plant physiology, animal science and medical science. There is no doubt that every living being has identical DNA sequence as the fundamental building block. And there are so many living beings which have no brain at all such as plant and microorganism, a few primitive types such as sponges and jellyfish which have no neuron cell (Seipel \& Schmid, 2005). For example, tomato knows how to grow and regulate flowing and the number of fruits being accommodated at given growing state and environments. It indicates that plant has awareness, and that plant has some types of consciousness through which it can sense and communicate with signals from root to leaves. Leaves send signals to the tip of the shoot telling them to start making flowers (Chamovitz \& Cook, 2012).

In this vein, we can say that awareness is a part of consciousness activities which can be classified as low level of consciousness spectrum.

\subsection{Movement of Consciousness}

In general, we are prone to sensing something in the outside world and responding to it. It means that information processing of signal transfers occur at every moment of our life (Lodish et al, 2000). In this regard, the primary concern is to investigate whether movement of the mind is observable, as is the case with materials such as electrons, atoms, molecules, and organs in a living body. And it is also important to know what type of movement is feasible among linear, spinning, orbiting, pulsing, bio-rhythm, waves, cycling of day-and-night, birth-and-death rhythms and so forth.

After confirmation of the movement, the search for the cause of movement will commence. The moving phenomena may be summarized as the following:

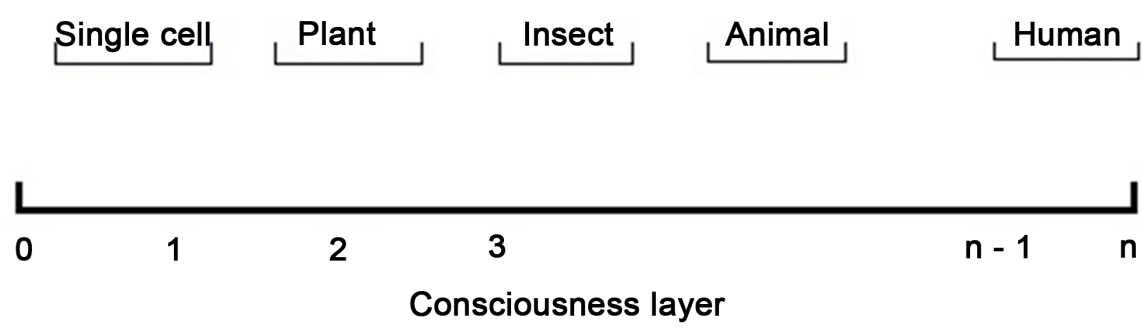

Figure 1. Classification of consciousness with the unified consciousness level or layer. 
-Everything in the universe is moving or changing in terms of existing states just like any substance on a moving ship does, because the ship is sailing on waves, over the sea.

-There are two types of movement: passive movement within a system and active movement independent of a system.

For example, a sailing ship belongs to active movement while the items in the ship are involved in passive movement. If one closely watches water in a cup, it seems to be static, but, in fact, it is in a dynamic state because electrons of water molecules are moving and, thus, we have to say that everything is involved in passive movement. In contrast, the observer does not move. From this we can see that movement is one aspect of the dualistic nature of phenomena. Given movement in a consciousness system, we face the fundamental question of how this is possible in the empty space of a non-material medium because any movement has to be described by a particle or wave of mass, as stated in quantum physics (Gasiorowicz, 1974).

Nevertheless, we can describe the movement in the consciousness system as the following:

-Direction of mind movement is not always straight, but involves a non-defaulted direction or path (e.g., thoughts of my child hinder other thought directions).

-Speed of mind is unpredictable; sometimes it is too fast or, in some cases, too slow to be measurable, and is beyond the concept of time and space (There appear to be no differences in thinking time between thinking about one child at home and the other abroad).

-Various states of mind arise from sensing an object outside and interlinked with the relevant subjective images inside the mind and, thus, they are interconnected (seeing, feeling, thought, awareness, speculation constitute a multi-level in-depth hierarchy).

These facts provide very valuable information for the development of consciousness theory because all phenomena in this universe are a representation of the mind, as seen in any chemical reaction where a reactant can be identified from the resultant products.

\section{Structure of Consciousness Mesh (CM) System}

\subsection{Overall Structure of CM-System}

In line with the above mentioned premises, the author has proposed the model of consciousness system and described its theoretical feasibility by referencing certain relevant cases (Chun, 2000, 2002). In short, the assumptions are that all material phenomena are constructed images in the consciousness system, and the structural properties of consciousness involve space and time.

Before discussing the consciousness system, there is the question of what it looks like. Is it shaped as a square or sphere? If consciousness is non-material and empty, how can we guess its shape? So far there is no answer. Author as- 
sumes that the consciousness system is shaped like a sphere because every existing biological being begun from an egg, wherein a round-shaped nucleus exists; furthermore, they are living on a round earth, with a round sun, while the earth spins in a circular orbit.

As long as life is inseparable from consciousness, the prime purpose of structural design have to be a protection of self against external environment, so called stealth function, and thus its size should be as small as possible to avoid the search of enemies.

Another vital factor is that it should have as many tools for the limited volume to insure permanent life span to survive from internal and external stress or pressure. Mechanical engineers know that the structure to meet these constrictions is a spherical shape.

So far as consciousness accommodates and controls living beings, consciousness may be spherical, just as a child takes after a parent. Consequently, the cross section structure of consciousness may be a sphere having multiple layers, as shown in Figure 2.

Once a hypothetical model has been constructed, we need to examine its context. Specialists have invented technical terms to explore context and underlying reality. Insofar as consciousness has an invisible nature, like emptiness, new terminologies are necessary to talk about what its structure and components are.

\subsection{Consciousness Fiber and Consciousness Mesh}

The first term with this regard is the consciousness fiber (CF) as the essential element, and it has an identical meaning to that of thought thread as illustrated in Figure 3.

For instance, when we encounter an emotional event, we are used to say an expression of "Touching" that means "a connecting" to our minds.

The second term is the consciousness mesh (CM), which is webbed by consciousness fibers, CFs. When two people talk face-to-face across a table, there will be a communication line called a CF. If they debate an issue, they can reach an agreement at an appropriate point of compromise, as illustrated in Figure $4(a)$.

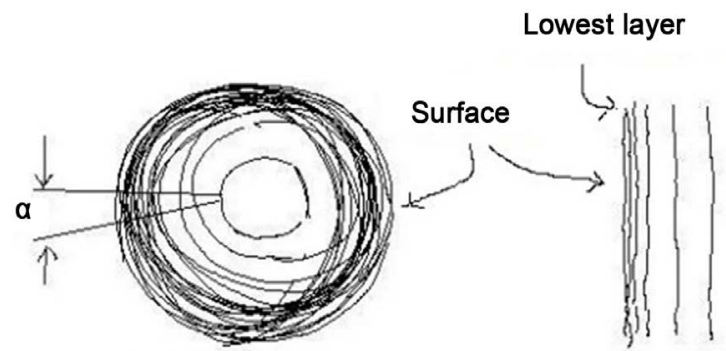

(a)

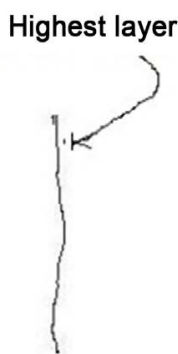

(b)

Figure 2. The hypothetical structure of consciousness. (a) Overall shape; (b) structure of section $\alpha$. 


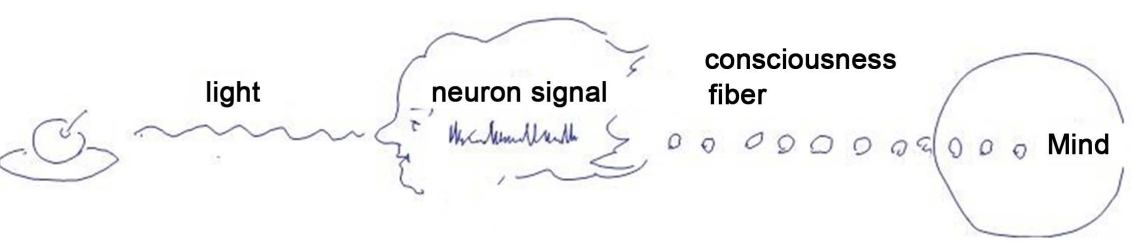

Figure 3. Consciousness fiber, CF, connecting the external and internal objects.

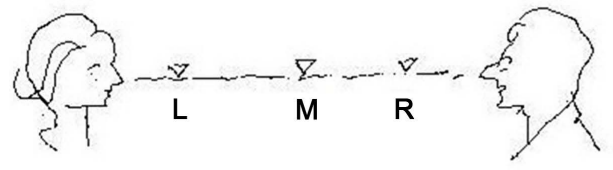

(a)

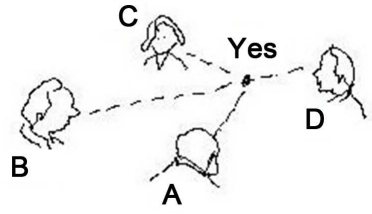

(b)

Figure 4. The feasible agreement node on CF between two and four persons. (a) CF formed between two persons; (b) node at point, "Yes" formed at crossing CFs between four persons.

If the distance between two people doubles, the $\mathrm{CF}$ is automatically doubled in length without breaking and, in this manner, the $\mathrm{CF}$ has a flexible nature as long as the communication continues. When two people agree perfectly, the agreement node occurs at the middle of the $\mathrm{CF}$ at $\mathrm{M}$, and if partial agreement in favor of one side is reached, the node will be located either to the left $(\mathrm{L})$ or right $(\mathrm{R})$, as seen in Figure 4(a).

If four persons are debating an issue, the agreement will occur to the point "Yes" after exchanging their thoughts; in other words, at the intersection point of two CFs of A-C and B-D, as illustrated in Figure 4(b). Accordingly, versatile geometrical structures of the consciousness mesh (CM) are easily shaped due to the flexible nature of the CF. Suppose several people are talking or sitting at a distance across a rectangular table from others; the consciousness fibers form a layer of $\mathrm{CM}$ (CM layer, $\mathrm{CML}$ ) composed of many unit $\mathrm{CM}(\mathrm{uCM})$, as illustrated in Figure 5.

The diversity of the shape of unit $\mathrm{CM}(\mathrm{uCM})$ can cause directional alteration of consciousness flow or transfer, which will be described later. The diversity of $\mathrm{uCM}$ comes from the nature of the consciousness agreement because the agreement is made by accepting the other's thought, whatever the degree, as is shown in Figure 4(b). Thus, we can produce a thinking connection, called CF, having starting, arrival, and nodal points in between. For instance, as we sit on chairs in a room in Seoul and exchange thoughts with a friend of NY about our sons and daughters, talking about their current job situations, will constitute another dimension or direction of the thinking thread, or $\mathrm{CF}$, resulting in a 3 dimensional CM (3D-CM) system.

As mentioned previously, CF and CM have flexibility in terms of time and space. This is the way the CM is constructed, and once consciousness meshes are shaped, they are fixed by the consciousness coherent force (C-coef, force acting at $\mathrm{CF}$ node), but varied with respect to size and shape, due to its flexible nature. The consciousness mesh (CM) concept arises from the fact that everything, from 


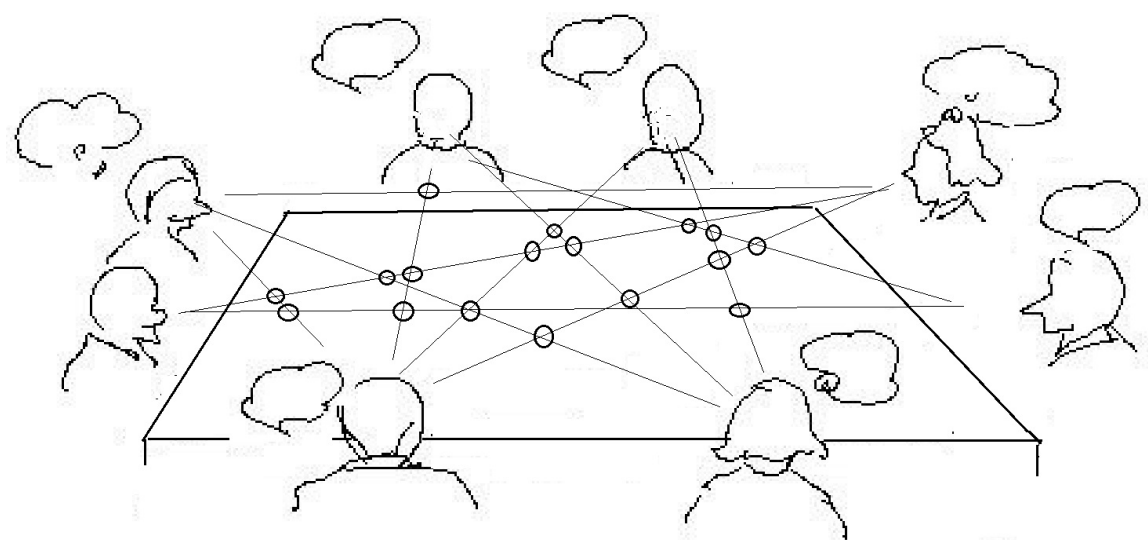

Figure 5. The diverse forms of uCM formed by several consciousness fibers.

an atom to the universe, resides in a closure-like cell membrane, capsule, or shell, whatever their sizes and surface appearances are. Assuming the consciousness world has a space, which is defined in a volumetric way, such as a 3dimensional scale, the space is filled with multiple shells or CM layers.

\subsection{Consciousness Mesh Layer}

The CM system is composed of a multi-layer consciousness mesh (mCML), which has different mesh size intervals; the smallest one at the bottom layer (outside) and the largest at the top layer (inside), as shown in Figure 6.

The small CM may be as small as an angstrom, to accommodate atoms, and the bigger one may be huge enough to hold stars or the galaxy. In between, uncountable numbers of CML of different sizes are positioned.

Humans may be positioned across several of the multiple consciousness layers, mCML. Due to the structural feature of multiple layers interlinked, layer after layer, we can imagine cubic cells or void spaces between the upper and lower layers. Accordingly, the 3D-CML contains a huge number of void spaces, to accommodate things of various sizes, just like a sponge block. In general, mesh has apertures or holes, and mesh is widely used to screen particles; the screening principle is based on the size of the apertures through which particles can pass (undersize) or not (oversize). The following are examples of technology applied to mesh devices: wire mesh, bio-mesh, bio-phore, bio-tubing, and so forth.

The finest mesh at the lowest CML (Figure 6(a)) is more likely to retain tiny beings in the relevant CML but, as the higher CML the larger beings are reside (Figure 6(b)), and thus such tiny beings are less likely to be retained by the bigger size of the mesh.

\subsection{Consciousness Coherent Force and Consciousness Fiber Fragment}

The third term is that of the consciousness coherent force (C-cohf) defined as a force acting on and around the $\mathrm{CM}$, by analogy to electrostatic force having positive and negative charges. Similarly $\mathrm{C}$-cohf has both attraction and repulsion 


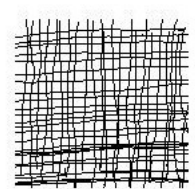

(a)

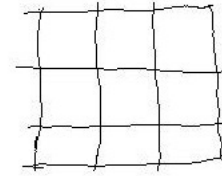

(b)

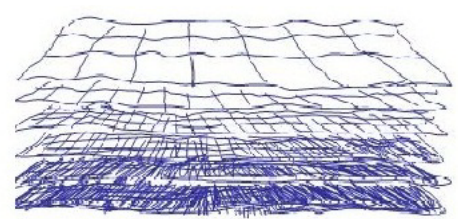

(c)

Figure 6. Structure of CM layer constructed with consciousness meshes. (a) Fine size $\mathrm{CM}$, fine mesh at bottom; (b) large size CM, large mesh at top layer; (c) multi-layer CM, multi-layered CM (mCML).

actions, by controlling directivity. When two CFs are agreeable, C-cohf makes them combine, forming a tied node and, if not, they repulse or reject each other. Given these forces, the CM has junction nodes. C-cohf enables two crossing CFs join together at some point, where two persons have agreed on something (Figure 4(b)), and plays to collect nearby CF and join. The node also serves to maintain the size of the mesh and spacing between the CM cells in the relevant layer and also the spacing between nearby layers (Figure 6(c)).

The exchange of thought constitutes communication with all its forms. In general, we communicate with words and sentences, but many unnecessary or meaningless sound words are inserted between sentences, such as "Eh, umm, yaa, ooh, etc" and body language. These types of expression are sometimes helpful for the continuation of talk, but would not be used in an official report. From the consciousness perspective, they constitute a fragment of the $\mathrm{CF}$, a socalled consciousness fiber fragment, CF-frag. The destination of CF-frags will be described in later sections. Given the C-cohf and flexibility of the CF, the CM attracts everything, including CF-frags and, at the same time, it produces $\mathrm{CF}-$ frags by repulsing the action of $\mathrm{C}$-cohf.

\section{Transfer Phenomena of Consciousness}

\subsection{Route of Consciousness Transfer}

If the consciousness system is filled with consciousness, we face the question of how thought travels because it corresponds to the case of a volume of water traveling through a water medium. To make a particular volume of water move apart from the surrounding water, energy pressure must be applied to the particular water volume of a given direction. In case of at the $\mathrm{x}$-axis flow will cause agitation phenomena in the medium because the cavity formed by the displacement of a mass has to be filled, and thus movement toward the y-axis results an agitation of medium due to the changes of potential and kinetic energy. The CM layer (CML) provides holes or tunnels that are filled with consciousness and thus, it seems that there is no room for thought to flow, as the case of water. Similarly, the motivation of any behavior like a talking and thinking something will serve as energy input in CML to produce agitation. A gap is, however, generated, momentarily, by passing a thought from one location (event) to another location while leaving some type of stress at surrounding areas. 
According to the intensity of a thought, the length and size of the gap are determined and the stress developed by the transfer impacts the surrounding medium wherein some type of sensible response occurs. The sensible product is a fragment of consciousness, the debris of the CML web. It is comparable to sailing a boat on a lake where there is nothing in the water but vanishing waves. However, sand dunes at the shore are affected and, on observing the state of the sand at the shore, we are aware that something may have happened in the middle of the lake. In this manner, consciousness fragments, CF-frags, are produced as the resulting product accompanying consciousness transfer.

Increasing the number of thoughts accounts for the continuing vibration of the entire CM system, producing more CF-frags.

\subsection{Property of Consciousness Transfer}

A possible way to grasp the consciousness flow is through the example of particular conductance, like copper and lead for electron transfer or glass fiber for light passage, as an analogy for neuron fiber and neuron signaling in the brain (Lodish et al., 2000). In such cases, medium disturbance can be minimized and kept from external influence, as observed in social communication and transportation systems. This is similar to neural signal transfer of neural fibers. Another concern is the speed and direction of the consciousness transfer; to cope with such situations, a conceptual approach will be needed to understand the dynamic movement of consciousness and the stream of consciousness.

We can imagine that the mind moves through a consciousness network, densely webbed all over the CM system, and that the particular structure of the web affects the speed and direction of transfer. Assuming that consciousness flows through the consciousness fiber (CF), a diagonal mesh structure of unit $\mathrm{CM}(\mathrm{uCM})$ will be served as transfer route of consciousness as shown in Figure 7.

The 3D structure of the unit $\mathrm{CM}(\mathrm{uCM})$ makes the transfer easy to navigate across various flow directions. Figure 8 illustrates how consciousness transfers take place both in horizontal and vertical directions at normal nodal alignments,

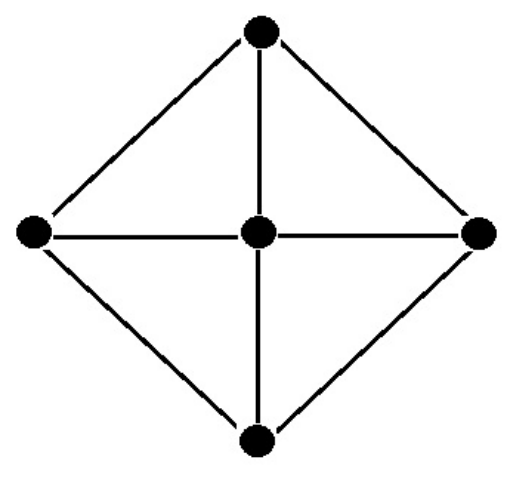

(a)

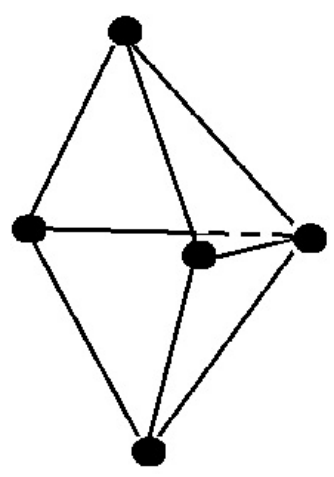

(b)

Figure 7. Nodal points in $\mathrm{uCM}$ and its geometric 3D alignment. (a) Nodes aligned in 2 dimension uCM; (b) nodes aligned in 3D uCM. 


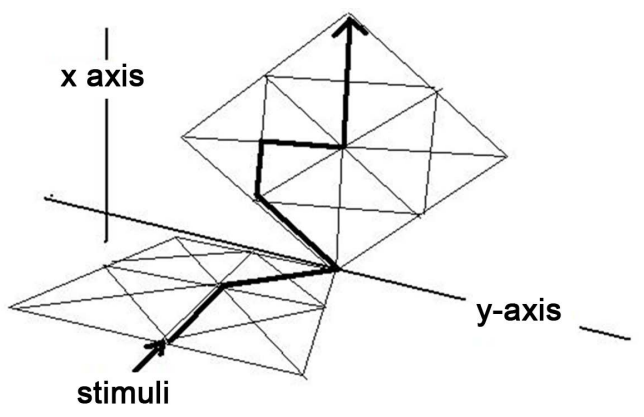

Figure 8. Consciousness flow along the 3D CM system composed of multiple uCMs. The thick solid arrow line refers to the passive route of the transfer.

and the changes in direction helps to link other layers above and underneath the uCM. Thus, we can imagine how many directional changes are possible through versatile passage routes as illustrated with the 3D alignment in Figure 8.

\section{Consciousness Realities in CM System}

\subsection{Consciousness Aggregate and Cluster}

Other important terminology is the consciousness aggregate (CA), which is essential for understanding further aspects of the CM system, focusing on the fundamental reality of self and subjective experience. Before mentioning the consciousness aggregate, we need to talk a little more about the CF-frag. According to the flexibility nature of the consciousness fiber, the CM slab has a flexible textural property, such as that seen in liquids or soft jelly. Any internal or external force impacts the slab, and the absorbed force spreads across the entire region of CML, many CF-frags are produced as the side product or waste.

The alteration of the shape or deformation affects the inner structure of the $\mathrm{CM}$ slab in terms of size and void space of the multiple CML (mCML), and results in irregular mesh and matrices nearby as illustrated in Figure 9.

Deformation includes such changes in unit $\mathrm{CM}(\mathrm{uCM})$ as stretching, contracting, or bending back and forth, and the bonding of CFs and CF fragments (CF-frag), due to repulsion-attraction by consciousness coherent force (C-cohf).

In this course, remarkable changes in the regularity of $\mathrm{uCM}$ with resulting structural aspects of form and size occur as illustrated in Figure 9(a) and Figure 9(b). In general, it causes the reduction of aperture size or void space, and provides more favorable rooms for CF-frag to be trapped inside the mesh (Figure 9(b)) than that of the original uCM (Figure 7). Besides the change in the size of $\mathrm{uCM}$, wave movement causes several significant changes in the CM system. One of the properties of the CM matrix is mystic force, called C-cohf, which attracts any floating CF-frag nearby.

The retained CF-frags aggregate each other to make a sizable conscious reality, called consciousness aggregate (CA) on a particular CM layer, as illustrated in Figure $9(\mathrm{c})$. As consciousness transfer increases, the number of the aggregate $\mathrm{CA}$ increase and, thus, the CA serves as the seed of transformation that bonds with nearby CAs to grow from an invisible consciousness reality to a sensible 


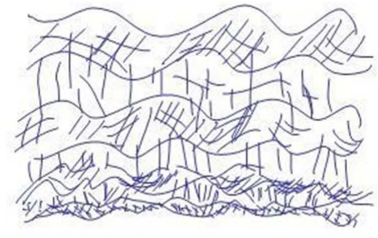

(a)

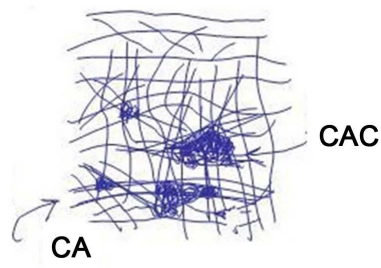

(c)

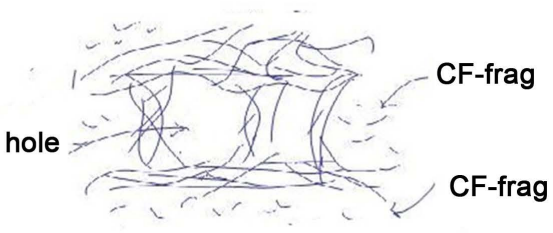

(b)

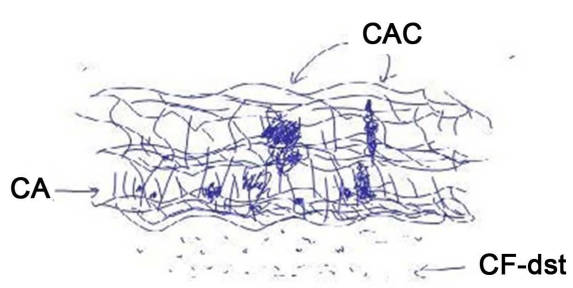

(d)

Figure 9. The formation procedure of $\mathrm{CA}$ and $\mathrm{CAC}$ in the $\mathrm{CM}$ system. (a) CML in movement; (b) holes and CF-frag in CML; (c) formation of CA and CAC in one CML; (d) $\mathrm{CA}, \mathrm{CAC}$, and CFs in $\mathrm{mCML}$.

clustered reality, or CA-cluster, CAC (Figure 9(d)) to be described in more detail later.

The formation of the CA takes place by probability or chance on a given CML environment. In other words, given the presence of $\mathrm{CA}$, there is the possibility of the presence of a sensible being, as a living being. In short, the conditions for the presence of life may be those of CA formation. The chance of CA formation is determined by the size and number of mesh as well as CF-frags available nearby.

The formulated identity CA serves as the basic unit for further development toward the basis of material substance: atoms, molecules, and materials of this universe. Thus, all existing matter such as soil, rock, and water is created in this manner in the CM system. The differences in material size of bio and non-bio materials are caused by differences in the size of CAs; the smaller in small CAs, the larger in large CAs. As an analogue of CA, consider the image of a volleyball player stretching out his or her arms and then the other members stretch their hands over to demonstrate their aggregated willingness to win the game.

\subsection{Formation of Consciousness Aggregate Cluster}

The growth direction of CA is not set, but varies upon circumstances, including the horizontal plane of one layer (a), the vertical bidirectional of upward and downward in a CML (c), and growth across CMLs (d) as illustrated in Figure 10.

The smaller size or void of the unit consciousness mesh ( $\mathrm{uCM}$ ), the more chances there are to form $\mathrm{CA}$. The CA combines or aggregates with neighbor CAs to increase its size to the extent that a big "CA reality" is formed, called a CA-cluster (CAC), as shown in Figure 10(a). The CAC continues to grow, reaching upper layers as illustrated in Figure 10(b). The growth of the CAC serves as a link between the CM layers, CMLs. The small CAC will be related to the size of small living beings, such as microbes (a). In contrast, the larger CAC 


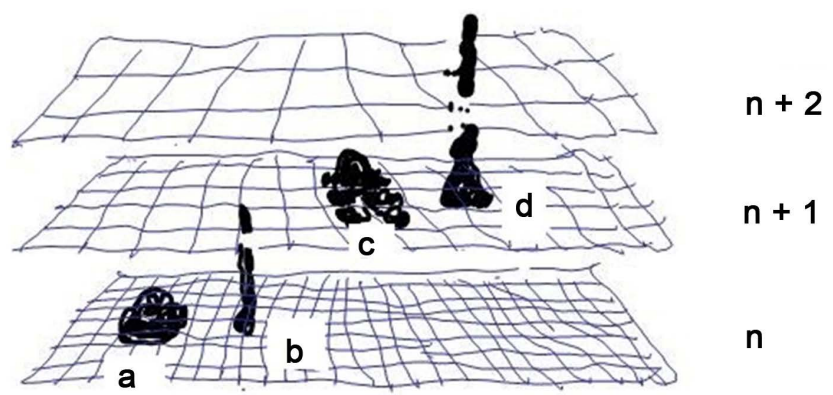

Figure 10. Comparison of CA column and CA-cluster, CAC, formed between CMLs. N + i denotes the number of CMLs. (a) CA at nth CML; (b) CAC formed between $\mathrm{n}$ and $\mathrm{n}+$ 1 th CMLs; (c) CA at $n+1$ th CML; (d) CAC formed between $n+1$ and $n+2$ th CMLs.

(c) will be related to larger living beings. Although CACs are the same in size, their natures are different, according to their relevant residential layer and place, CML, in terms of role and capability, as may be seen in two CACs at nth and $\mathrm{n}+1$ th CMLs at (b) and (d) in Figure 10. In this regard, all beings in this universe constitute the $\mathrm{CAC}$, formed in the $\mathrm{CM}$ system, whatever their forms are.

Politicians are well aware of the impact of CAC and thus are likely to induce mass rally at public squares to pursue political aims. Furthermore, we know the impact of mass media, which can transform mass aggregated opinion on policy.

\subsection{Recycling of CF-Frag and CF-Dust}

We think continuously throughout our lifetime and, thus, a new CM layer is generated as illustrated in Figure 5. Insofar as the number of CML is fixed, the oldest one has to be discharged from the $\mathrm{CM}$ framework by decomposing itself into fragments, CF-frags. These CF-frags are recycled into CA at other layers where CAs and CACs need CF-frags for further growth in other CM layers. It means that the end points of $\mathrm{CA}$ and $\mathrm{CAC}$ are found in the same outgoing layer.

The finest CF-frag, to be retained by the densest CML, accordingly the CFdust can not be a consciousness reality of CM system so long as the cycle of CAC is concerned. However, CF-dust converts itself into mass that can combine with CAC-to become a mass-bound CAC, or CACM, which will be also described later.

\section{Hierarchy of CAC and the Self}

\subsection{CAC Potential}

The CAC reality (Figure 10) may be used to define the hierarchical nature of the self on the basis of its height and layers rooted. The small CAC at nth CML belongs to a lower living being such as a microorganism. The taller CAC, at a higher $\mathrm{n}+1$ th CML, has more capability for formulating intellectual beings; the comparison here is like the difference between insects and humans. From the capability perspective, there are two types of CAC; the CAC at the growth state tagged by $\mathrm{CAC}+$ at growth state and CAC-at the decay state as shown in Figure 11. 


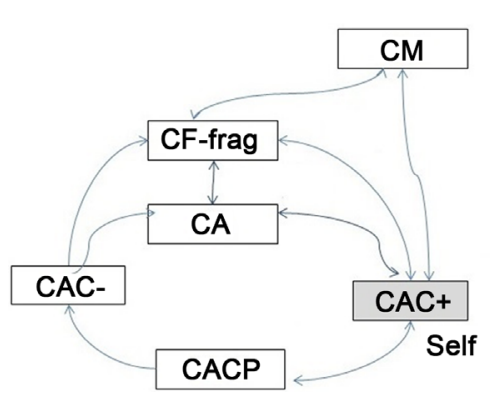

(a)

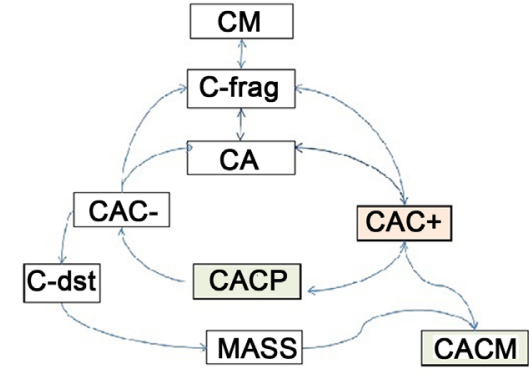

(b)

Figure 11. The formation of the self in CM system and transfer routes of various consciousness realities. (a) Life cycle of non-mass bound CAC, CACM; (b) life cycle after mass bound state, CACM.

As CAC grows, its capability in terms of intelligence develops to awareness of its own presence as an identity called the "Self", whereby subjectivity and objectivity are first shaped. As Descartes said, "I think, therefore I am.” (Malcolm, 1965).

Accordingly, the self is the CAC constructed through several processing steps shaping a life cycle in the CM system;

CF-frag $\rightarrow$ CA formation $\rightarrow$ CAC formation $\rightarrow$ Intelligent $\rightarrow$ Self $\rightarrow$ subjectivity and objectivity $\rightarrow \mathrm{CAC} \rightarrow \mathrm{CF}$-frag or CF-dust.

Consciousness realities exist on various grades in CAC, such as microorganism, plants, insects, and animals. The main characteristics of these beings may be classified in terms of their capability of movement. Mold and plant are nonmobile or rooted and, thus, their activities zones are limited to a fixed zone within a few square centimeters. On the other hand insects and animals, including birds, have the capability to move across several acres. According to the concept of CAC potential (CACP), the higher-intelligent being has the bigger CAC, which can be defined by the height of CAC per unit zone or uCM. Humans have relatively wide activity zones, due to having the highest intelligence or the biggest CAC. Thus, the difference in the activity zones of beings is not determined by type of life in the biological kingdom but by activity zone, or intelligence. Therefore, the CAC potential (CACP, see Figure 11) or capability of beings should be rated by the activity zone, or intelligence, and it means that the original source of CF-frag whether from low or high CML. The CAC formed with CF-frag at higher CML poses higher capability.

\subsection{Relationship between CAC and Material}

Suppose a couple moved into a new house and found the dining room empty. They look around the dining room, thinking that it should be equipped with a dining table. The couple are in agreement on their thought (CA); they will continue in this thought agreement process as they consider the desirable size, color, price of the table, and so forth ( $\mathrm{CA} \rightarrow \mathrm{CAC}$ ). These exchanges of thought develop into a clear idea of the desired table_CAC, which leads to the purchase of a table. At here, a dining table is considered to be CAC-because it is no longer a 
living being.

Ahead any action and motivation, the relevant $\mathrm{CAC}+$, emerges from the couple's mind. In this way, the presence of any material thing, CAC-Material, defined as CACM, in the world is the manifestation of consciousness reality or CAC in a given CM layer or society. In this regard the table purchased is the CACM appeared in dining room.

\subsection{CAC Mass-Based and CAC Potential Perspectives}

The term CACM refers to a hypothetical construct reality that manifests itself in a sensible identity or as materialized self. The distribution phenomena of CACM are generally observed in scientific data onto, for example, world distribution and population of plants and animals. The biomass populations are depicted in the world surface map, which is comparable to one CML of the mCML. This tells us that the earth_CACM accommodates versatile plant_CACMs and animal_CACMs. It is pertinent for living beings, and CACM exists in accordance with the material size basis. The distributions of plant species are affected by the elevation of land, and it indicates that the types of CACMs are distributed differently, from CML to CML, depending on environmental factors such as altitude, temperature, and climate.

Thus, from this perspective, everything, including humans, is the product of CACM, determined by versatile CAC sizes, and amounts of bounded mass. This is the reason why plants cannot grow at high altitudes, where there are no tiny CACM. For example, galaxy, galaxy_CACM is accommodated in the relevant huge universe_CACM, and human_CACM resides in its corresponding CML. Various organs inside humans are also positioned in their relevant spaces, in line with the human_CACM. The distribution and population of the universe including solar planets and living beings is nothing more than the parts of CAC in CM systems, and are shaped as they are. However, this hypothesis cannot yet answer the problem of how human_CACM can control a massive elephant_CACM or catch a huge whale_CACM.

Before mentioning CAC potential (CACP), I would like to note that CACP has an insensible nature because it is not bounded with mass; rather, it is a highly concentrated CAC, which has little room or void space for any mass to reside. Therefore, it is easy for CACP to return to its origin in the CM system whenever the environmental conditions are met. As CAC grows, it can expand across the interlayer of multi-layered consciousness, mCML. The bigger the CAC, the wider the scope or area it has, and this potential increases in the same way as the view from an observation tower. When living beings are categorized by CACP, their relevant positions in the $\mathrm{mCML}$ will be quite different from those of CACM. From the perspective of CACP, humans are placed at the top of the animal kingdom, controlling this world.

How is it that tiny animal coexist with huge animals? Prey and predators in the food chain can be explained by the CACP approach. Considering the invisibility of CACP, which has more capability than CACM, the consciousness sys- 
tem is run by capability basis in a hierarchical multi-layered operation system.

For instance, humans can control huge animals such as elephants and whales, which are several times bigger than humans on the basis of CACM. Accordingly, prey-and-predator relationship can be validated by the CACP logic.

\section{Consciousness Processing}

\subsection{Three-Way Branching Perception in CML Model}

We live by making decisions and choosing the best option among others in a given context. Is there any ubiquitous law regarding making the best choice? It means that self has to choose one out of multiple options. Reverse engineering has been widely applied as a way of establishing the technological principles of a device, object, or system (Eilam \& Chikofsky, 2007), which we can trace back to its fundamental state through analysis of its structure, function, and operation. Using this perspective, Author attempted to generalize a rule of choice at four different academic fields: chemistry, physics, biology, social science, and computer science as illustrated with Figure 12.

In chemistry, carbon is the most fundamental element in living beings, and it has four covalent bonds with which it can bind to other elements, from hydrogen to large molecules such as amino acids, carbohydrates, and proteins.

In biology, genetic code plays a key role in determining the destination of life by means of a so called triplet code, with codons consisting of three bases coded for specific amino acids, which are the building blocks of protein (Crick et al., 1961). The triplet code is composed of the combinations of four bases: Adenine, Cytosine, Guanine and Thymine. The form of life is determined by the choice of these bases. In physics, driving car at a cross section of road, we are used to choose one particular way of four options, stop, go straight, turn to the left or the right.

In many social researches including tests in school, the multiple-choice format, choosing one out of four options, is most frequently. These types of choice can be defined as either a three-way-branching-transfer (3-WBT) in general or a three-way-branching-perception (3-WBP), in perception process.

People with different past experiences of food exhibit different feelings regarding the in-take of the food. This suggests that "mind food", the experience of food, defined as Exp_CACM, in their memories affects the individual sensory response to food. Three-way-branching-perception (3-WBP) occurs during the perception process, in CML system.

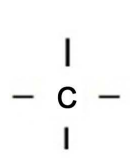

(a)

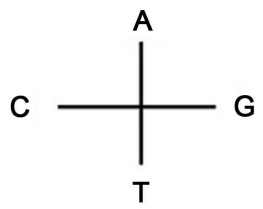

(b)

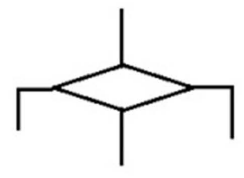

(c)

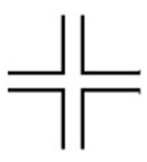

(d)

Figure 12. Common features of multiple choice. (a) Carbon; (b) gene codon; (c) programming; (d) cross road. 
Figure 13 shows how the external stimuli of food are perceived through biased transformation steps to generate feelings (Figure 13(a)) (Chun, 2000, 2001). The 3-WBP is similar to Alternative Forced Choice (Thurstone, 1927; Ennis, 1998), but different in its consecutive process of branching. As a consequence, the perception is biased toward the direction where the dominant memories of food, Exp_CAC, are preserved.

Therefore, the apple that I have eaten leaves traces to my CML, as shown in Figure 13(c), where I, myself, also reside in the same CM web as marked with arrow in Figure 13(d). Similar model was proposed by Lamme (2004) to explain visual attention and visual consciousness as shown in Figure 14.

An input stimuli perceive as indicated with thick arrow (a) and two inputs are arrived to brain they are separately transfer (b) and left for a while in the memory area as marked with gray area (c) where recurrent processing take place to reach up to visual cortex hierarchy.

The similarity between the above two models suggests the feasibility of the validity of 3-WBP logic is very promising.
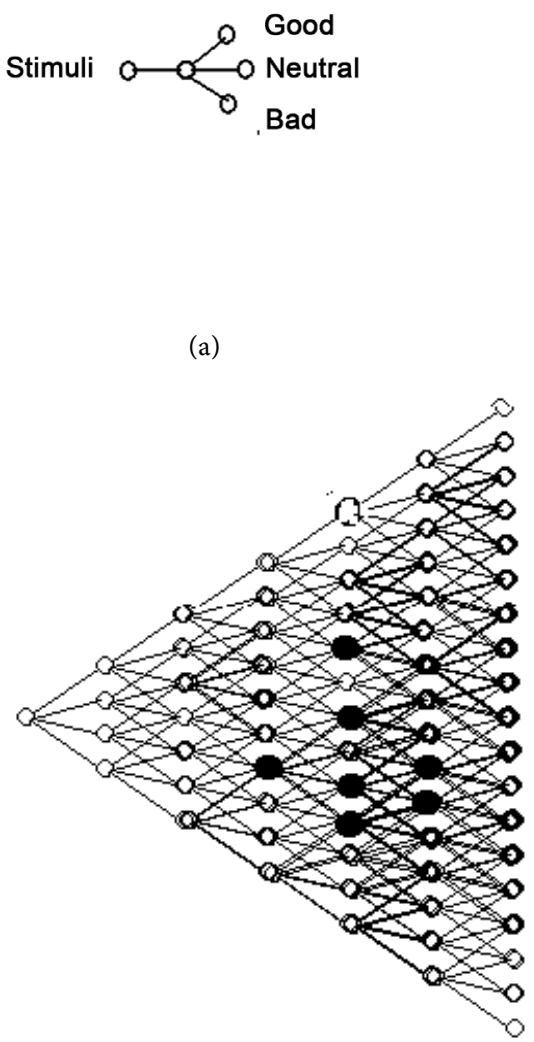

(c)
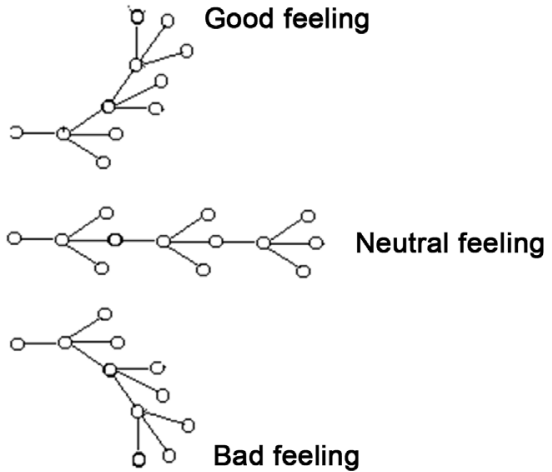

Bad feeling

(b)

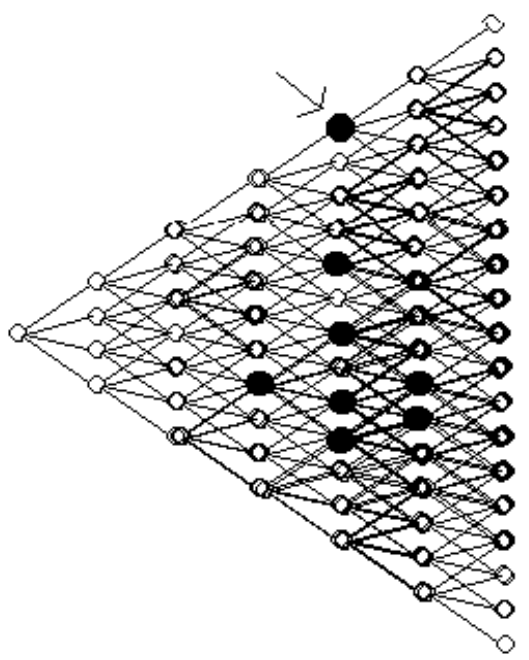

(d)

Figure 13. Schematic illustration of the consciousness process steps with 3-way branching perception mechanism. (a) 3-WBP; (b) three steps 3-WBP; (c) data stored in 3-WBP network; (d) the self formed in the network as marked by arrow. 


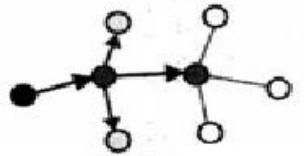

(a)

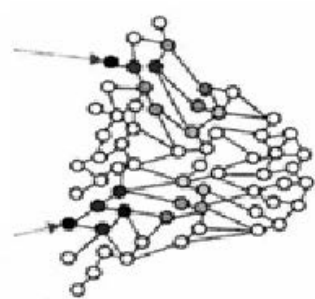

(b)

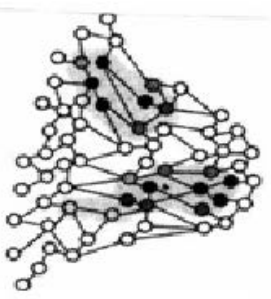

(c)

Figure 14. Lamme's model of neural image of visual perception. Arrow indicates input stimuli. Cited in Lamme (2004). (a) Stimuli transfer; (b) visual input fed; (c) memory stored shaded areas.

\subsection{Food Acceptance Process Based on Vasubandhu's Theory}

The perspective that the mind is composed of multiple CML (mCML) and process is based on 3-WBP, the existence of multiple stages of perception or inter-perception is possible. Vasubandhu (400 AD) presented a model of multistage perceptions known as consciousness-only or mere consciousness theory (Anacker, 1984). He claimed that humans operate in a multilayered, hierarchical structure of consciousness consisting of 4 consciousness layers; three layers (6CL, 7-CL and 8-CL) operate in higher levels and one sensual layer (5-CL) consisted of 5 sensorial consciousness, operates in the bottom level. His theory is a particular case of human being among many other consciousness beings operated by $\mathrm{CM}$ theory.

Chun (2002; Chun \& Cho, 2011) proposed "The pathway of consciousness Flow" and its simplified one is schematically illustrated in Figure 15, to show how the system of consciousness interfaces with the external world and generates motivation in the internal world. In neuroscience field, multi perception process was found in primary visual cortex (Paradiso, 2002).

For instance, food acceptance processing is operated in $\mathrm{mCML}$ consisted of 4 CMLs (5, 6, 7, and $8 \mathrm{CL})$ as illustrated in Figure 15.

\subsection{Virtual Food as Virtual Reality in the CM System}

Perspectives resting on a mCML approach acknowledge that multiple senses are involved in the perception stage; the concept of virtual food was introduced to explain the intermediate process in the world of consciousness (Chun, 2003). Virtual food (VF), food-in-mind, mediates the transfer of food-related events among CMLs and emerges from the issues listed in Table 1.

Like the biochemical synthetic process, reactions are taking place in a sequential manner, and a precursor is required to proceed; VF is needed for food substances to elicit the consciousness reaction. Soon after food is digested, its physical shape collapses leaving behind sensorial stimuli, and it undergoes transformations, passing through multiple perceptions, as part of a sequential process, a stage by stage inter-perception between consciousness layers, CML by CML. Therefore, VF is further classified into three types; VF1, VF2, and VF3, which are engaged as precursors of 5-CL and 6-CL, 6-CL and 7-CL, and 7-CL and 8CL, respectively. 


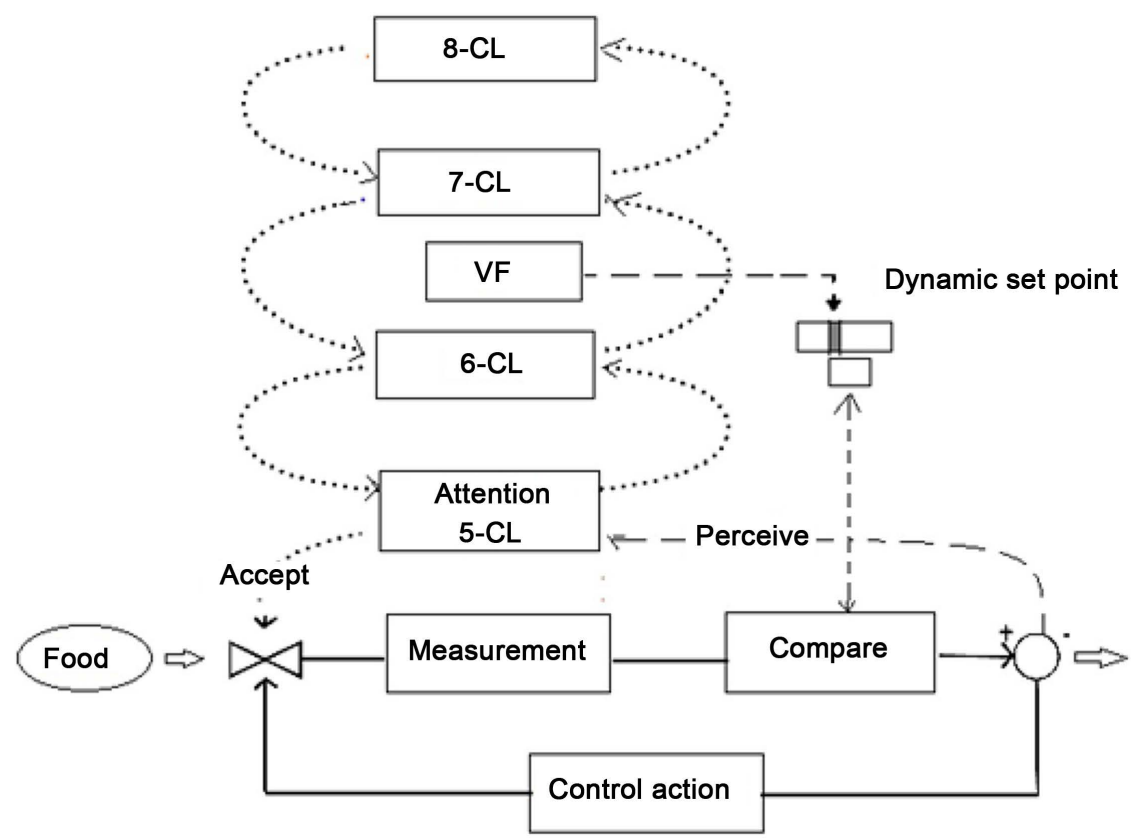

Figure 15. Food Acceptance processing model composed of four conscousness layers 8-CL, 7-CL, 6-CL and a feedback loop operating in 5-CL. VF refers to virtual food in mind.

Table 1. Food and non-food related issues in the cognitive sensory evaluation of food.

\begin{tabular}{|c|c|c|}
\hline Component & Issues & Contents \\
\hline Environment & $\begin{array}{l}\text { Objective } \\
\text { Issue }\end{array}$ & $\begin{array}{l}\text { Brightness, temperature, humidity, } \\
\text { audio-factor, visual-factor }\end{array}$ \\
\hline $\begin{array}{l}\text { Product } \\
\text { property }\end{array}$ & & Taste, flavor, shape, color, chewing sound, texture. \\
\hline $5-\mathrm{CL}$ & $\begin{array}{l}\text { Subjective } \\
\text { Issue }\end{array}$ & $\begin{array}{l}\text { Gender, age, weight, height, hunger, health } \\
\text { (eye, ear, nose, tongue, mouth, stomach) } \\
\text { sensitivity of sense organs, smoking and preference } \\
\text { associated with five senses. }\end{array}$ \\
\hline 6-CL & & $\begin{array}{l}\text { Schema }{ }^{*} \text {, effect of schema }{ }^{*} \text {, knowledge of product, } \\
\text { information, family education, education, concentration. }\end{array}$ \\
\hline 7-CL & & $\begin{array}{l}\text { Age of first eat, frequency of eating, cooking } \\
\text { experience, ability of association, direction of } \\
\text { association, preference of family, hobby, first impression, } \\
\text { demand of unconsciousness state, ideology, feeling } \\
\text { after eating, faith, rationality, religious teaching, } \\
\text { frequency of dreaming, similarity of eating habit. }\end{array}$ \\
\hline $8-\mathrm{CL}$ & & $\begin{array}{l}\text { Eating while pregnant, given digestibility, willingness, } \\
\text { awareness of mind, frequency of meditation. }\end{array}$ \\
\hline
\end{tabular}

From the perspective of CAC, VF1, VF2 and VF3 are equivalent to the experiences of CAC and CACP in its lifecycle, Exp_CAC, and Exp_CACP, respectively.

Virtual food influences preference and acceptance, and serves as the funda- 
mental frame of reference to decision making and consumption of food. When a food is a good match with the virtual food held in mind, it will be accepted; if it is not good match, the food will be rejected. Thus, non-substance virtual food may play an important role in shaping expectations about food. Figure 16 illustrates VFs in the mCML process related to food consumption.

Virtual foods can elicit insensible subjective experiences associated with perception stages. Therefore, the response to the external world will be similarly affected by VF under the influence of CACP in terms of the hierarchical aspects.

In general, the mind states so called emotion, mood, pleasure and sorrow are considered that they are determined by variables and factors such as personality and environmental circumstances. Several studies have demonstrated that people automatically evaluate all stimuli (social and nonsocial objects and events) as either good or bad (Fazio et al., 1986; Bargh et al., 1996). The automatic terms suggest that there is a well-established system on working in our consciousness system. Thus, any food-related behavior may be regarded as the outcome of perception process like a food reward (Berthoud et al., 2011) via 3-WBP across mCML.

\section{Application of CM Theory to Food Related Issues}

\subsection{Cognitive Sensory Evaluation of Food}

Since any event does not occur independently but affected by various causal factors in both internal and external worlds, the classification of such factors into the relevant layer of consciousness, CML, is necessary to understand the real cause. Various approaches to characterizing the mental interactions among contextualized signals have been reported (Booth \& Freeman, 1993; Bruns \& Grunert, 1995; Booth, 2008; Booth et al., 2008). To disentangle the causes of taste, Chun (2002) and, Jin and Chun (2004) classified food and non-food issues into two categories pertaining to elements of consciousness; objective and subjective issues according to Vasubandhu's logic as defined in Table 1.

The objective category primarily includes those attributes of food addressed by food sensory science (Meilgaard et al., 2006); the subjective category also includes some issues that can be assessed by conventional sensory tests. And it includes non-food related issues like lifestyle, and personality. In order to clarify

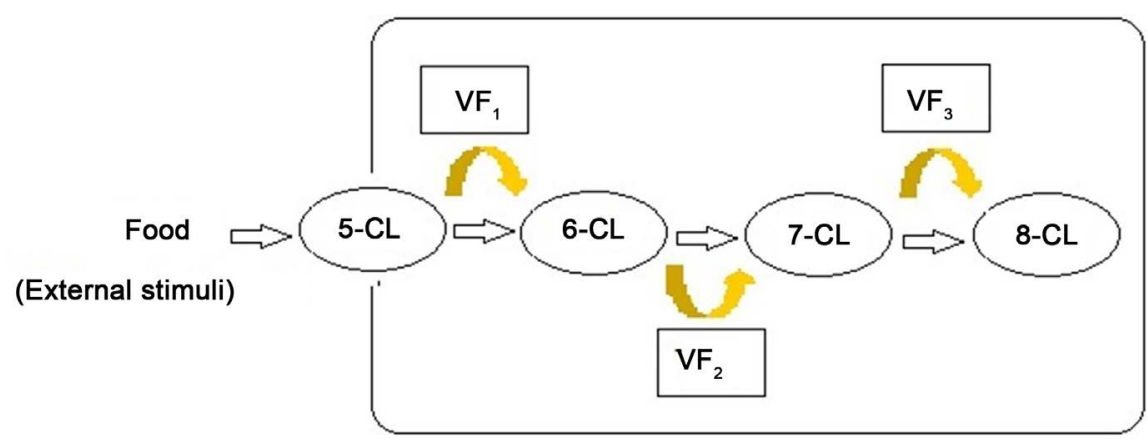

Figure 16. Schematic illustration of Virtual Food in mCML inter-perception. 
the psychological reactions that affect food choice and acceptance, it is necessary to understand how food-related and non-food related stimuli are cognitively merged into the stream of consciousness. The current sensory evaluation of food has the weakness for limitation of testing by sensory organs without revealing mind states arising from consuming food. In this regard, the cognitive sensory evaluation, CSE method based on the concept of mCML with 3-WBP logic was proposed by author (Chun, 2002). The terminology 'Cognitive' is more oriented to decision maker, self, than sensing organ at reception step serving acquiring input data. When tasting a food, we try it first, and followed by judgement whether it is familiar or not based on the similarity between one and the other reminding from past experiences, and also concern about following reaction and so on. Therefore, evaluating food acceptance is different from conventional sensory evaluations. According to Vasubandhu's multi-layered consciousness (mCML) theory (Anacker, 1984), conventional sensory evaluations tap the sensory responses of respondents at low levels of consciousness, called 5-CL and 6CL (Chun, 2000, 2001). From this perspective, cognitive sensory evaluation (CSE) of food acceptance is based on full consciousness levels including higher levels of consciousness, namely 7-CL and 8-CL. We can grasp the relationship between food-related complexities and food-related behavior of individual consumers using the mCML approach.

The contents of questionnaire for cognitive sensory (CSQ) evaluation were designed to inquire the responses of the issues in Table 1 as described elsewhere (Chun, 2000, 2002; Shine \& Chun, 2004), and the response to the survey has been presented in terms of cognitive sensory barcode (CSB) and cognitive sensory frequencies (CSF, not shown at here because the conversion is need additional procedure), as shown in Figure 17.

The irregular Overall Cognitive Sensory Barcode, OCCB pattern is the characteristic perception of food, which represents the overall cognitive sensory responses of an individual subject and reflects both subjective and objective sensory issues as listed in Table 1 . The height of the bar represents the degree of

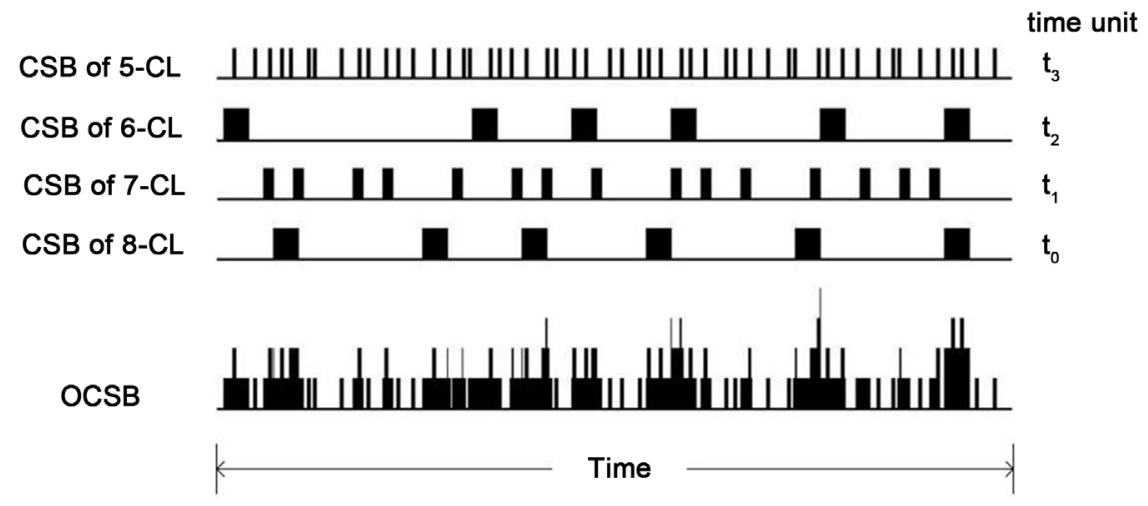

Figure 17. Cognitive sensory barcode constructed for the consumption of a food item by an individual subject. Timer 0 through Timer 3 refers to the clocks working with different time unit t0, t1, t2, t3, in 8-CL, 7-CL, 6-CL and 5-CL, respectively. CSB: Cognitive Sensory Barcode. OCSB: Overall CSB. 
association with consciousness, which is resulted from the occurrence of overlapping among the consciousness layers. The pattern is more strength than numerical score rating sensorial response in many aspects including quantity of data, image cognition and communication as seen commercial barcodes. Barcode and barcode reader so powerful influences on our daily life including documentation, data processing, commercial trade and accounting in bank.

\section{Case study 1. Cognitive sensory evaluation of drinks}

Food acceptance by consumers plays an important role in the choice and purchase of food. However, it is difficult to predict the preferences for individuals and groups of consumers unless their context is understood, including factors such as food centeredness, geological environment, cultural traditions, and social aspects of food preferences. Thus, a simplified method of cognitive sensory evaluation was developed using questionnaires based on four dimensions of food related and non-related consciousness.

Two surveys were conducted: first one to categorize consumers into subgroups with respect to their responses regarding consciousness factors, and second one to develop a Cognitive Sensory Evaluation Table (CSET), which was then applied for practical use.

\subsection{Simplified Questionnaire for Cognitive Sensory Evaluation}

The original CSQ was designed to assess consumers' evaluation of the taste of food. A 7-point rating scale was used which was based on three-way branch perception (3-WBP) at 5-CL, and 3-WBP at high levels of consciousness including 6-, 7-, and 8-CL. However, the CSQ including 148 items was too complex and took a long time to complete. Thus, we attempted to simplify the questionnaire by reducing the number of questions.

The simplified Cognitive Sensory Questionnaire (sCSQ) was designed to encompass four dimensions of the layers of consciousness, which consist of 11 consciousness components, called componential factors. Each factor includes three items as illustrated in Table 2 showing 2 consciousness layers; 7-CL and 8-CL as the examples.

\section{A Survey method}

The sCSQ was applicable to any food item, and particular questions could be added for a given food item. The sCSQ was internally consistent, as $70 \%$ of the scales had Cronbach's alpha values $>0.6$. The factor analysis with varimax rotation revealed that the 11 consciousness factors accounted for $57.6 \%$ of the variance in the questionnaire, demonstrating the structural validity of the sCSQ consciousness factors.

\section{1) Subjects and Sample Foods}

The sCSQ survey was administered to 826 participants representing three income levels: high (24\%); middle (44.5\%); and low income (31\%0. Of these, $27.2 \%$ were high school graduates, $28.0 \%$ were junior college graduates, and $44.7 \%$ were university graduates. 
Table 2. Simplified cognitive sensory questionnaire of 7 and 8 CLs.

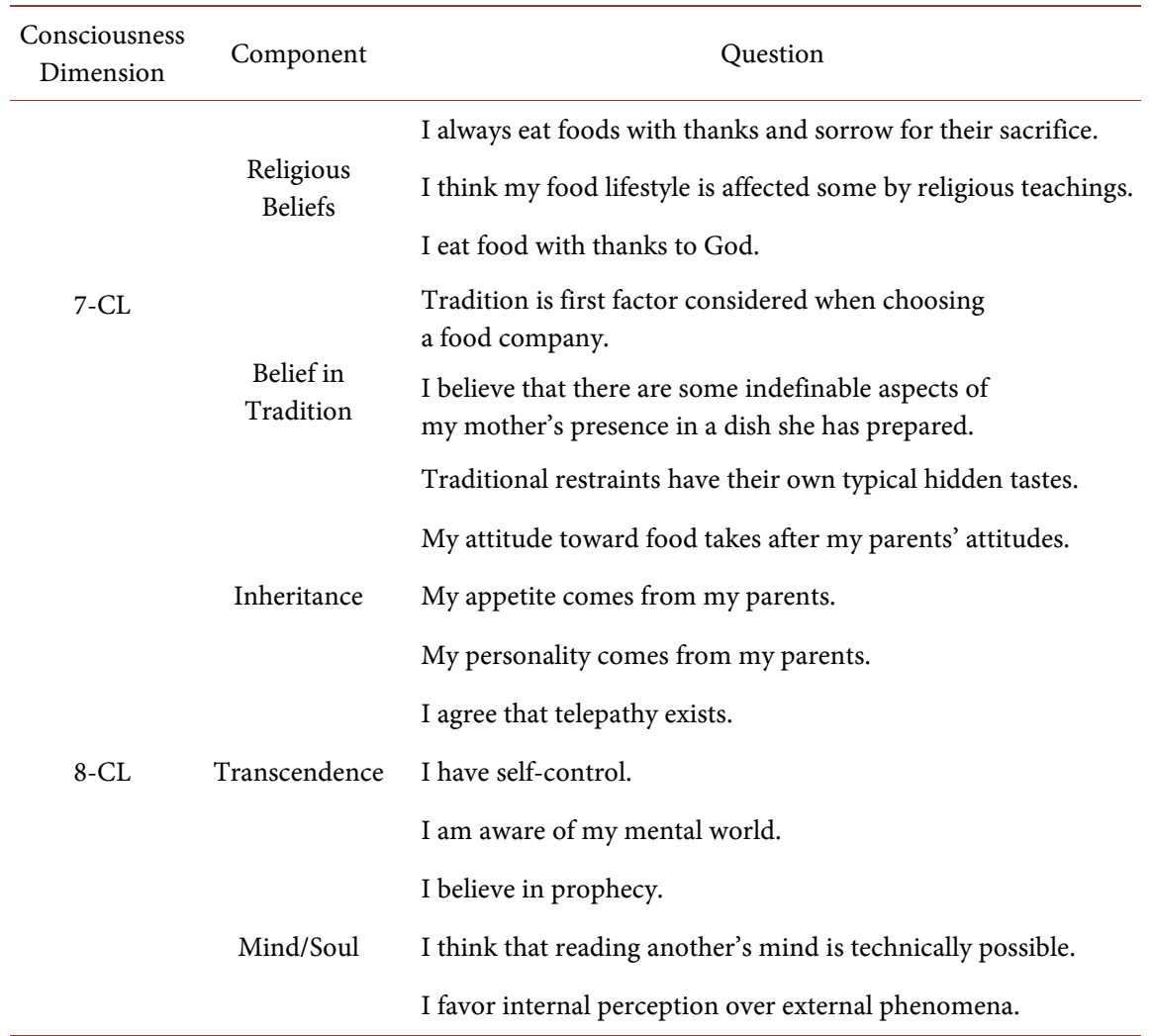

Their ages ranged from 30 to 60 years; $37.9 \%$ were in their 30 s, $31.1 \%$ in their 40 s, and $31.0 \%$ in their 50s. They included housewives that did not work outside the home (65\%) and jobholders (35\%).

The subjects were from southwest, southeast, northwest, and northeast districts of Seoul. Each district was represented by $>200$ participants. Questions about the attitudes toward Korean wheat products were included in the SCSQ.

\section{2) Procedure to create the CSET pattern}

The Cognitive Sensory Evaluation Table, CSET, is composed of six columns and 14 rows that match the numbers of question or component consciousness factors as shown in Table 2 and the detailes of the table was described elsewhere (Cho et al., 2012) (Figure 18).

Black or grey filling in the triangle represents positive and negative influences, respectively. Both triangle and numeric figures are presented for ease of recognition by readers. As depicted in the completed CSET, the intensity of influence of the associated factors can be recognized at a glance.

\section{B. Survey Results}

Further simplified coverall CSET, OCSET, was used to present and As indicated in the CSET, potato chips are highly affected by $5-\mathrm{CL}$, and the taste factor is associated with the 7-CL. For practical application a simplified CSET, called OCSET was developed as shown in Figure 19.

Comparing the OCSETs of the eight food items tested, peppermint candy and sport drink-PA were closely associated with 5-CL and in contrast, coffee is re- 


\begin{tabular}{|c|c|c|c|c|c|c|c|}
\hline & & Over & Accept & & & & \\
\hline & & & & Comp & ntial Ac & tance & 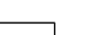 \\
\hline & & Overall & Vision & Smell & Taste & Touch & Sound \\
\hline & Health & & 0.75 & & & & \\
\hline CL & Sensitivity & $\widehat{1.28}$ & 1.06 & & & 1.18 & $1.2 x$ \\
\hline & $\begin{array}{c}\text { Concept of } \\
\text { Taste }\end{array}$ & 0.72 & 0.78 & 0.50 & 0.93 & 0.78 & 0.91 \\
\hline 6-CL & $\begin{array}{l}\text { Knowledge } \\
\text { of Product }\end{array}$ & 1.28 & 1.28 & & 2.89 & 0.40 & \\
\hline & $\begin{array}{l}\text { Knowledge } \\
\text { of Taste }\end{array}$ & 0.91 & 0.67 & $1.2 x$ & 1.20 & 1.09 & 0.43 \\
\hline & $\begin{array}{c}\text { Religious } \\
\text { Belief }\end{array}$ & $0 \neq 2$ & Lot & 1.18 & 0.26 & 0276 & 0.39 \\
\hline & $\begin{array}{l}\text { Belief of } \\
\text { Tradition }\end{array}$ & $\widehat{1.42}$ & 1.26 & $1.1 x$ & & 0.97 & 1.21 \\
\hline & Associations & 0.96 & $\widehat{1.4}$ & 0.93 & & 1.11 & 1.05 \\
\hline $1-C L$ & Habits & $\widehat{1.45}$ & $\widehat{1.44}$ & $\widehat{1.35}$ & 1.11 & 1.11 & $\widehat{1.36}$ \\
\hline & $\begin{array}{c}\text { Rational } \\
\text { Desire }\end{array}$ & 0.88 & 1.13 & $\widehat{1.49}$ & 0.96 & 100 & $0 . \hat{32}$ \\
\hline & $\begin{array}{l}\text { Instinctive } \\
\text { Desire }\end{array}$ & 0.87 & $\widehat{A .4 \lambda}$ & 1.21 & 0.88 & 0.55 & 0.08 \\
\hline & Inheritance & 0.57 & $0 \longdiv { 7 2 }$ & 1.09 & 0.17 & 0.64 & 0.54 \\
\hline 8-CL & Transcendence & $\widehat{A .4 \lambda}$ & $\widehat{1.43}$ & & 1.45 & 104 & 0.86 \\
\hline & Mind/Soul & 0.56 & 1.35 & 2.99 & 0.63 & 0.22 & 0.50 \\
\hline
\end{tabular}

Figure 18. The completed CSET of potato chip. The dimension and componential factor of consciousness and the category of acceptances are presented at the left and top of the Table, respectively.

lated to upper consciousness layers 7-CL and 8-CL. Peppermint candy is uniformly rated in the component of sound across the entire dimensions. Through the completed OCSET we could understand from where and how food acceptance are originated and associated both sensorial and consciousness components.

For instance, coffee is very helpful drink for insight internal mind and associated with intelligent working such as writing and planning something, and in contrast, it is not recommendable for sportsmen that are relied on the intensive sensory response. 

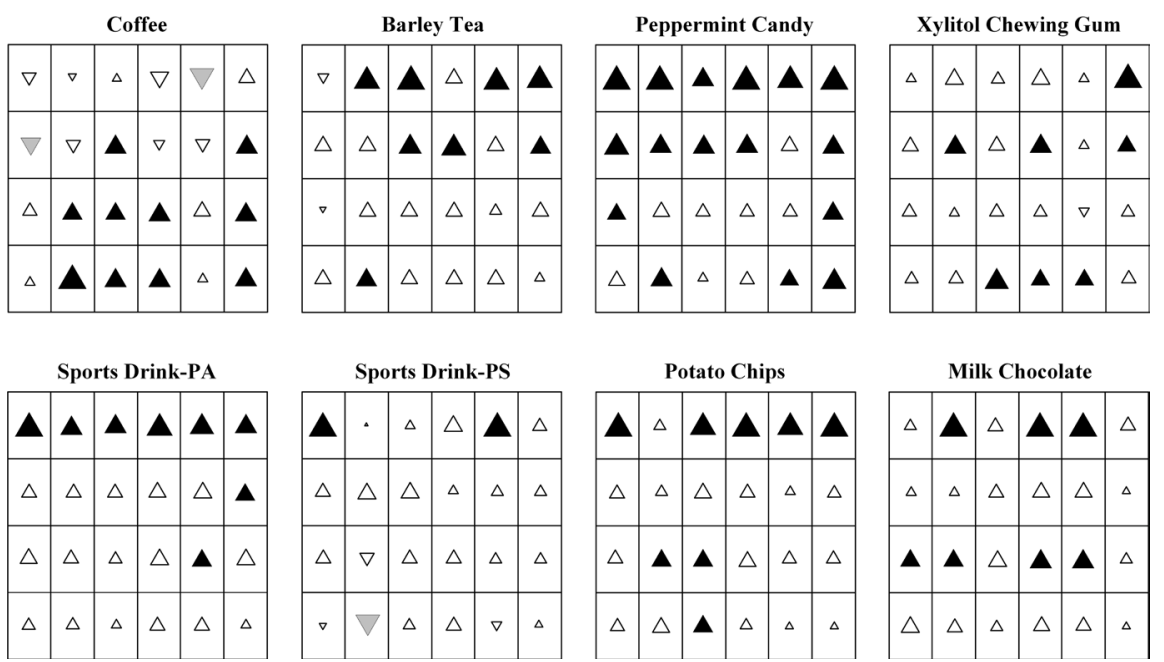

Figure 19. Overall cognitive sensory evaluation table, OCSET, of eight food items.

The OCSET is a kind of pattern image recognizable at a glance like a weather map showing size and density of cloud which forcast state of weather of a district. And it will be one of the alternative method presenting consumer's responses to food and other fields.

Case Study 2. Interpretation of Morning sickness of pregnant women

Pregnancy is a unique life-creating phenomenon, but the mother herself, does not know when another self, baby_CACP, comes to her, mom_CACP, until particular symptoms (mass increased as baby_CACM and mom_CACM) appear after some time. One of the symptoms is Emesis gravidarum (EB), known as a morning sickness, which affects the appetite and taste perception of food, which has to be shared between two selves; mom_CACM and baby_CACM. Since the pregnancy progresses unconsciously, the mCML approach is necessary for understanding what and how consciousness layers are involved and processed, and it sheds important light on what is happening in the world of consciousness. This is the reason why a comparison study is needed between pregnant and nonpregnant experienced women groups.

Appetite has been extensively studied in conjunction with human health problems such as illness and obesity; however, little is known about the fetus. In general, pregnancy experiences Emesis gravidarum (EG), (Bowen, 1992; Ortega, 2001). In consciousness perspective, the emergence of life of a new baby_CAC starts with a fertilized cell, dad_CAC and mom_CAC, and grows into an entire body, baby_CACM, characterized by an increasingly complex neurological system that controls itself as illustrated with Figure 20.

During the pregnancy period, nutrients are supplied through the mother's digestion system for two purposes: one to support the mother (mom_CACM) and fetus (baby_CACM), and the other to support the construction of the new neural network, which seems to progress outside of the consciousness of the mother, mom_CACP (Figure 20(a)). In the absence of an adequate neuronal system, the fetus shares the mother's communications network as a member of the mom CACP family. This tells us that the baby_CACP is under the activity zone of 


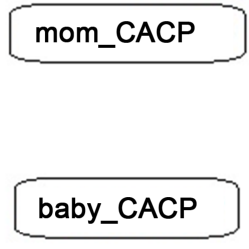

(a)

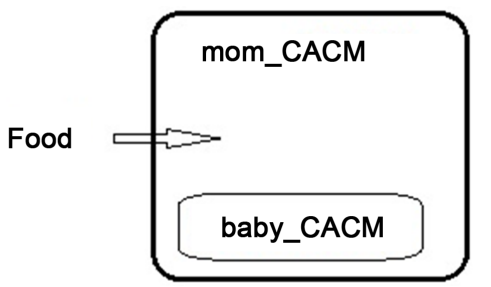

(b)

Figure 20. Changes of the state of self upon pregnancy. (a) CACP states; (b) CACM states.

mom_CACP (Figure 20(b)). This situation strongly implies that two lives reside in the fertilized cell (mom_CACP and baby-CACP) and participate in controlling the entire life course, including food consumption.

It would be difficult to assert that mothers and fetus have identical mind; thus, the newcomer baby_CACP must have moved in with its own subjective experiences Exp_CAC codified into genetic codes, containing its experience history encoded in 8-CL in terms of Exp_CAC and Exp_CACP experiences.

The author hypothesized that pregnant women would experience a phenomenal change in appetite caused by underlying CAC changes as well as changes in the environment CML (Exp_CAC and Exp_CACP) including external and internal phenomena such as physiological programming (Exp_CACP). Events in 5-CL and 6-CL may represent the environment of the self, or 7-CL. The genetic record emerging from previous generations (Exp_CAC and Exp_CACP) affects the mother's food-related behaviors (Exp_CACM), including those involved in the morning sickness during pregnancy.

One remarkable change in appetite is found among pregnant women in morning sickness. This particular food behavior has been accepted as a natural phenomenon that occurs in the early stages of pregnancy and disappears as the pregnancy advances. However, this change is not merely a physiological phenomenon, and rather it involves a significant change in the food evaluation process that affects food appetite and acceptance which are closely associated with food taste, choice, consumption and health (Lim, 2005).

\section{A. Survey Method}

\section{Cognitive Sensory Questionnaire for Pregnancy Survey}

The CSQ addresses all items defined in Table 1. It consisted of questions about the subjective category, including questions on information about subject issues about health and lifestyle, about food attitude and behavior, regarding particular experience regarding pregnancies. It also included questions about feeling, satisfaction for each component, and overall satisfaction after consumption of food. The CSQ test does not restrict environmental conditions because the internal environment is too complex to control; for instance, 5-CL and 6-CL may be the environments for the egocentric 7-CL.

The questions on the CSQ test are illustrated as the followings with the answers to the bracket.

Objective category, referred to 5-CL: What is the color of the potato chips? 
(white, white-yellowish, yellow, brownish-yellow, brown); Did you have any change in appetite?; Was there any change in quantity of your meal? (not at all, slightly, quite, much, very much).

Subjective category, referred to 6-CL, 7-CL, and 8-CL: How much do you know about potato chips? (nothing at all, little, fair, much, and very much) for 6-CL; How responsive are you toward a new food? (not at all, little, fair, much, and very much), What does eating potato chips to cause you to imagine? (nothing at all, potato or fruit, bear, friends, event or business) for 7-CL; How often have you eaten potato chips while pregnant? (not at all, quite seldom, seldom, often, very often); Do you have any dreams particularly associated with pregnancy? (not at all, quite seldom, seldom, often, very often) for 8-CL. Componential and overall satisfaction: Do you like the color of the potato chip? (extremely dislike, dislike, slightly dislike, neutral, slightly like, like, extremely like).

The subjects and food items included in the CSQ should be selected in consideration of consciousness issues for subject groups who had differently experienced by particular event with regard to a typical food item; for example, potato chips on which subjects have a wide range of age with different exposure periods for a certain subject group.

\section{B. Survey Results}

In order to investigate the effect of pregnancy on personal life style, respondents composed of 2 groups: Non experience pregnancy, PN ( $n=98)$ and experience pregnacy, $\mathrm{PY}(\mathrm{n}=65)$ groups were clustered into four food-related-lifestyle (FRL) groups: (Lim et al., 2008).

Group-L1 (adventurous), Group-L2 (rational), Group-L3 (conservative), and Group-L4 (uninvolved) by applying segmentation method (Bredahl \& Grunert, 1997) (see legends in Figure 21). There is a significant association between food-

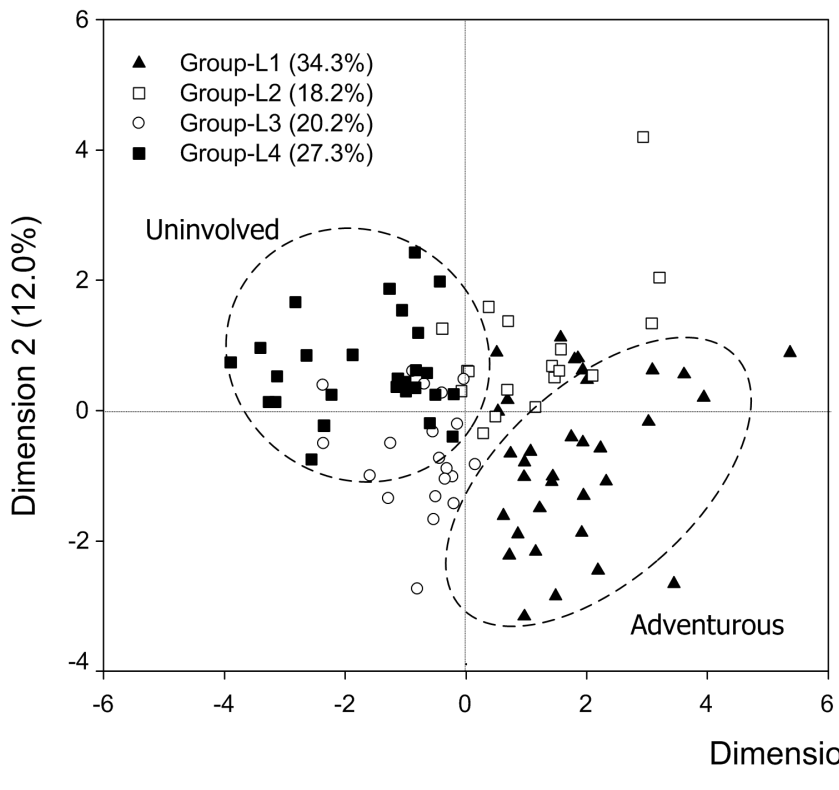

(a)

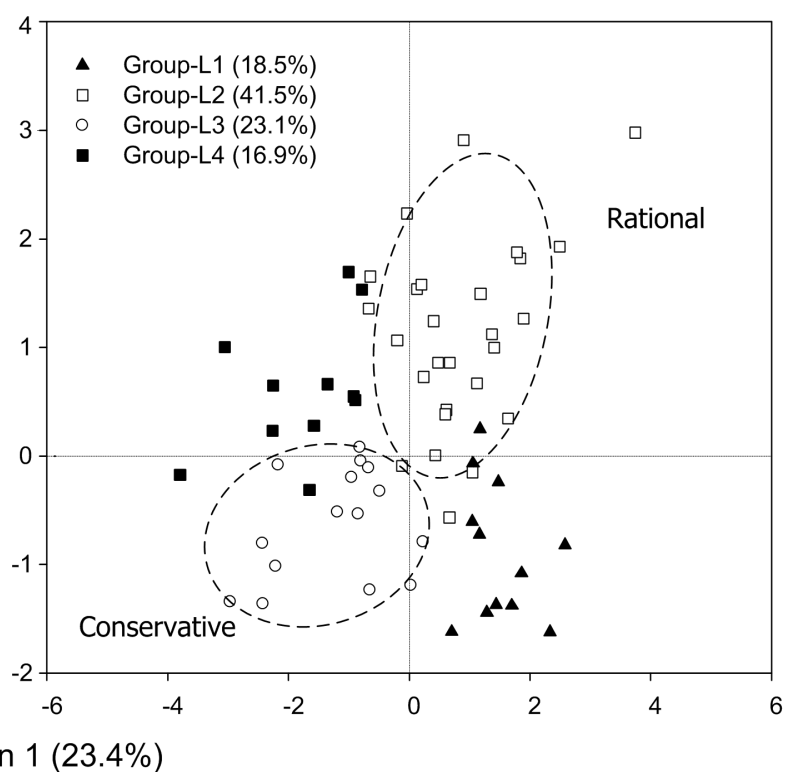

(b)

Figure 21. Food-related lifestyle cluster representations of PN $(n=98)(a)$ and PY $(n=65)(b)$ subjects in terms of the first two dimensions of the multiple factor analysis. 
related lifestyle and experience of pregnancy (chi-square $=16.53, p<0.001$ ). As much as $41.5 \%$ of the PY group were placed into Group-L2, and nearly onequarter (23.1\%) were classified into Group-L3 (see dotted circle in Figure 21(b)), whereas slightly over one-third (34.3\%) of the PN group was classified as Group-L1, and more than one-quarter (27.3\%) were placed into Group-L4 (see dotted circle in Figure 21(a)).

Members of the PY group were more prevalent (64.6\%) than those in the PN group (38.4\%) among those leading rational and conservative lifestyles. The results strongly suggest that the pregnancy experience, Exp_CACP may account for compromises in food-related decisions affected by rational and conservative considerations. The rationality comes from non-egoistic thought rooted at 8-CL as Exp_CAC and conservative one is based on cumulated experience and similarity of CACP family. In this context pregnant experience enhances non-selfish CACP family.

Cross checking Cognitive Sensory Evaluation with Food-Related Life style Instrument.

The CSE questionnaire, CSQ, was comparatively examined by the FRL questionnaire (Scholderer et al., 2004) which was based on a hierarchical cognitive structure (Grunert \& Grunert, 1995; Gutman, 1982). The comparison showed that almost all the issues covered by the FRL were related to the behaviors caused by combinations of several CMLs, as shown in Table 3.

Accordingly, data obtained within the FRL measurement using the meansends approach to consumer behavior (Olson \& Reynolds, 1983) was consistent with the proposed causal role played by consciousness of self at the upper level of the mCML hierarchy. In addition, 5-CL and 6-CL were similar to the bottom level of the FRL framework, which was associated with situation-specific input at the stage of perceiving an external object. Therefore, lifestyle can be considered an outcome of a consciousness inter-perception process controlled by egoistic personal values constructed at 7-CL. The PY group obtained high scores for both women's tasks (mean score, 3.97) and specialty shops (4.42), whereas the PN group obtained high scores of five dimensions: whole family (4.92), security (4.67), enjoyment of shopping (4.95), interest in cooking (4.76), and social relationships (5.40). With regard to Chun's mCML approach, four of the seven dimensions were associated with 7-CL alone, and only one dimension was associated with 6-CL. These analyses showed that significant differences between the $\mathrm{PN}$ and PY groups in the dimensions considered to be the most important may have resulted from the involvement of 7-CL rather from that of 5-CL and 6-CL.In summary, any substantial food-related behavioral differences in the two groups was determined by the hierarchical top-down process of consciousness.

As reflected on the MDS positional plots illustrating food acceptance (Figure 22(a)) and food consumption (Figure 22(b)) among PN and PY groups, the responses from PN subjects were densely concentrated in a narrow and limited zone of the sphere plots and in contrast, those of PY subjects were widely scattered across the sphere as shown in Figure 22. 
Table 3. Significant differences between PN and PY groups on the FRL survey and associations with components of CML

\begin{tabular}{|c|c|c|c|c|c|c|}
\hline \multirow{2}{*}{ FRL Dimension } & \multirow{2}{*}{ t value } & \multirow{2}{*}{$p$ value } & \multicolumn{4}{|c|}{ Involvement of $\mathrm{CML}(\mathrm{O})$} \\
\hline & & & 5-CL & 6-CL & 7-CL & $8-\mathrm{CL}$ \\
\hline Freshness $^{\mathrm{a}}$ & 1.35 & 0.18 & & $\mathrm{O}$ & $\mathrm{O}$ & \\
\hline Health $^{\mathrm{a}}$ & 0.68 & 0.50 & & $\mathrm{O}$ & $\mathrm{O}$ & \\
\hline Novelty $^{\mathrm{a}}$ & -1.61 & 0.11 & & $\mathrm{O}$ & $\mathrm{O}$ & \\
\hline Organic products ${ }^{\mathrm{a}}$ & 1.14 & 0.25 & & $\mathrm{O}$ & $\mathrm{O}$ & $\mathrm{O}$ \\
\hline Price/quality relation ${ }^{a}$ & 1.06 & 0.29 & & $\mathrm{O}$ & $\mathrm{O}$ & \\
\hline Taste & -0.51 & 0.61 & $\mathrm{O}$ & & $\mathrm{O}$ & \\
\hline Security ${ }^{b}$ & -3.81 & $<0.001$ & & & $\mathrm{O}$ & \\
\hline Self-fulfillment in food & -1.77 & 0.08 & $\mathrm{O}$ & & $\mathrm{O}$ & \\
\hline Social relationships ${ }^{\mathrm{b}}$ & -2.58 & $<0.05$ & & & $\mathrm{O}$ & \\
\hline Convenience & -1.58 & 0.12 & $\mathrm{O}$ & & $\mathrm{O}$ & $\mathrm{O}$ \\
\hline Interest in cooking ${ }^{\mathrm{b}}$ & -2.50 & $<0.05$ & & & $\mathrm{O}$ & \\
\hline Looking for new ways ${ }^{\mathrm{a}}$ & 0.35 & 0.73 & & $\mathrm{O}$ & $\mathrm{O}$ & \\
\hline Planning ${ }^{\mathrm{a}}$ & -0.08 & 0.94 & $\mathrm{O}$ & $\mathrm{O}$ & $\mathrm{O}$ & \\
\hline Whole family & -7.28 & $<0.001$ & & & $\mathrm{O}$ & $\mathrm{O}$ \\
\hline Woman's task ${ }^{\mathrm{b}}$ & 7.49 & $<0.001$ & & & $\mathrm{O}$ & \\
\hline Attitudes to advertising ${ }^{\mathrm{a}}$ & -0.11 & 0.91 & & $\mathrm{O}$ & $\mathrm{O}$ & \\
\hline Enjoyment from shopping & -3.00 & $<0.01$ & $\mathrm{O}$ & & $\mathrm{O}$ & \\
\hline Price criteria a & 0.37 & 0.71 & & $\mathrm{O}$ & & \\
\hline Importance of product information ${ }^{a}$ & 1.96 & 0.05 & & $\mathrm{O}$ & $\mathrm{O}$ & \\
\hline Shopping list ${ }^{\mathrm{a}}$ & -0.71 & 0.48 & & $\mathrm{O}$ & $\mathrm{O}$ & \\
\hline Specialty shops ${ }^{\mathrm{a}}$ & 3.73 & $<0.001$ & & $\mathrm{O}$ & $\mathrm{O}$ & $\mathrm{O}$ \\
\hline Social event ${ }^{a}$ & 0.83 & 0.41 & $\mathrm{O}$ & $\mathrm{O}$ & $\mathrm{O}$ & \\
\hline Snacks versus meals & $\underline{0.46}$ & $\underline{0.65}$ & $\underline{\mathrm{O}}$ & & $\underline{\mathrm{O}}$ & \\
\hline
\end{tabular}

"a" refers to the dimensions relation to 6-CL, "b" refers to the dimensions related to 7-CL.

The pattern of responses to questions about food consumption differed from that to questions about food acceptance. These differences suggest that the experience of pregnancy shifts attitudes about food toward broader food consumption because the motivations behind food-related decisions become more focused on the entire family, CACP family.

On the basis of data obtained from the survey derived from Chun's concept of causal consciousness and from the FRL which was based on actual behaviors (Scholderer et al., 2004). We found that the experience of pregnancy affected food-related attitudes and behaviors including food preferences, choices, consumption, and satisfaction.

This comparative study of two groups of women, PY and PN, yielded two distinct facts: EG significantly affects food consumption, and the influence of EG is 
PN $(n=98)$

PY $(n=65)$
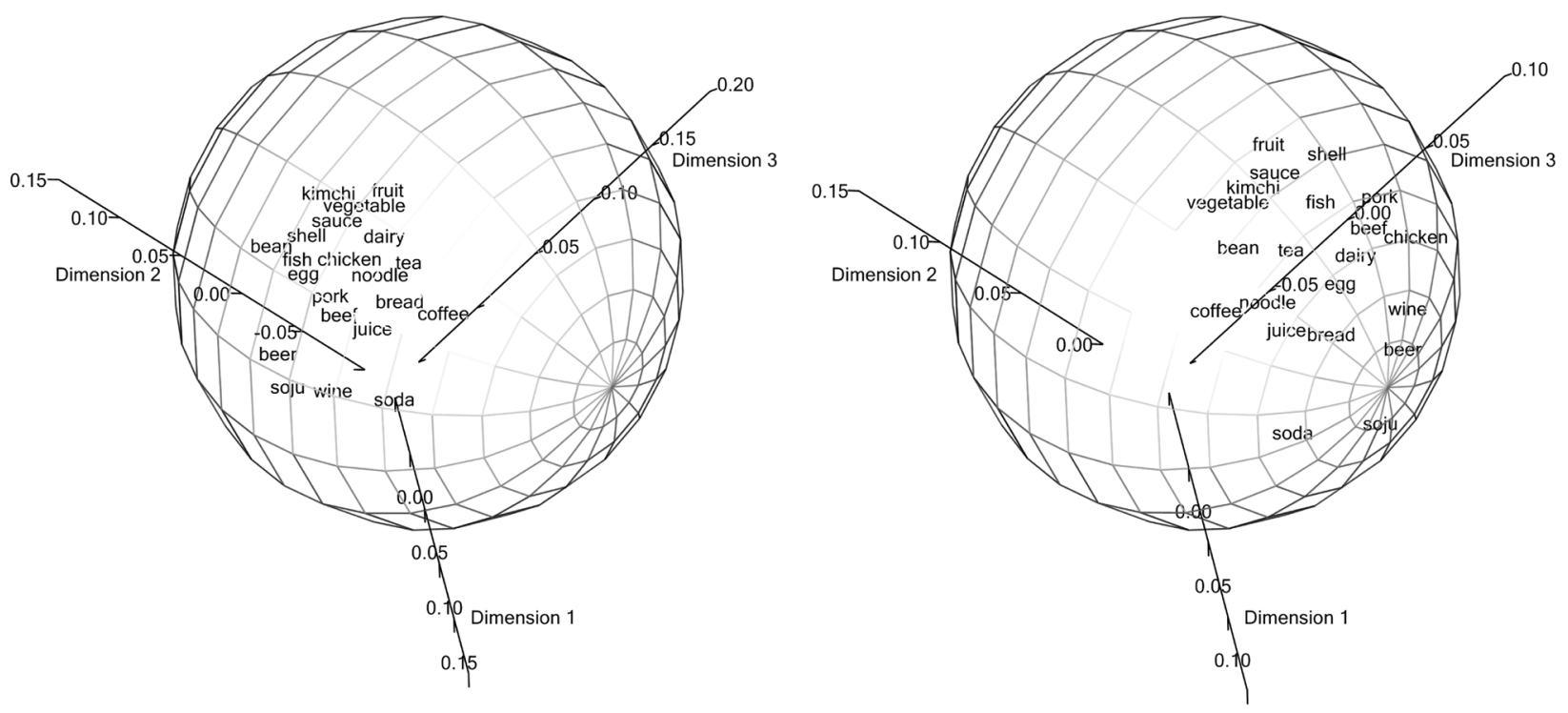

(a)
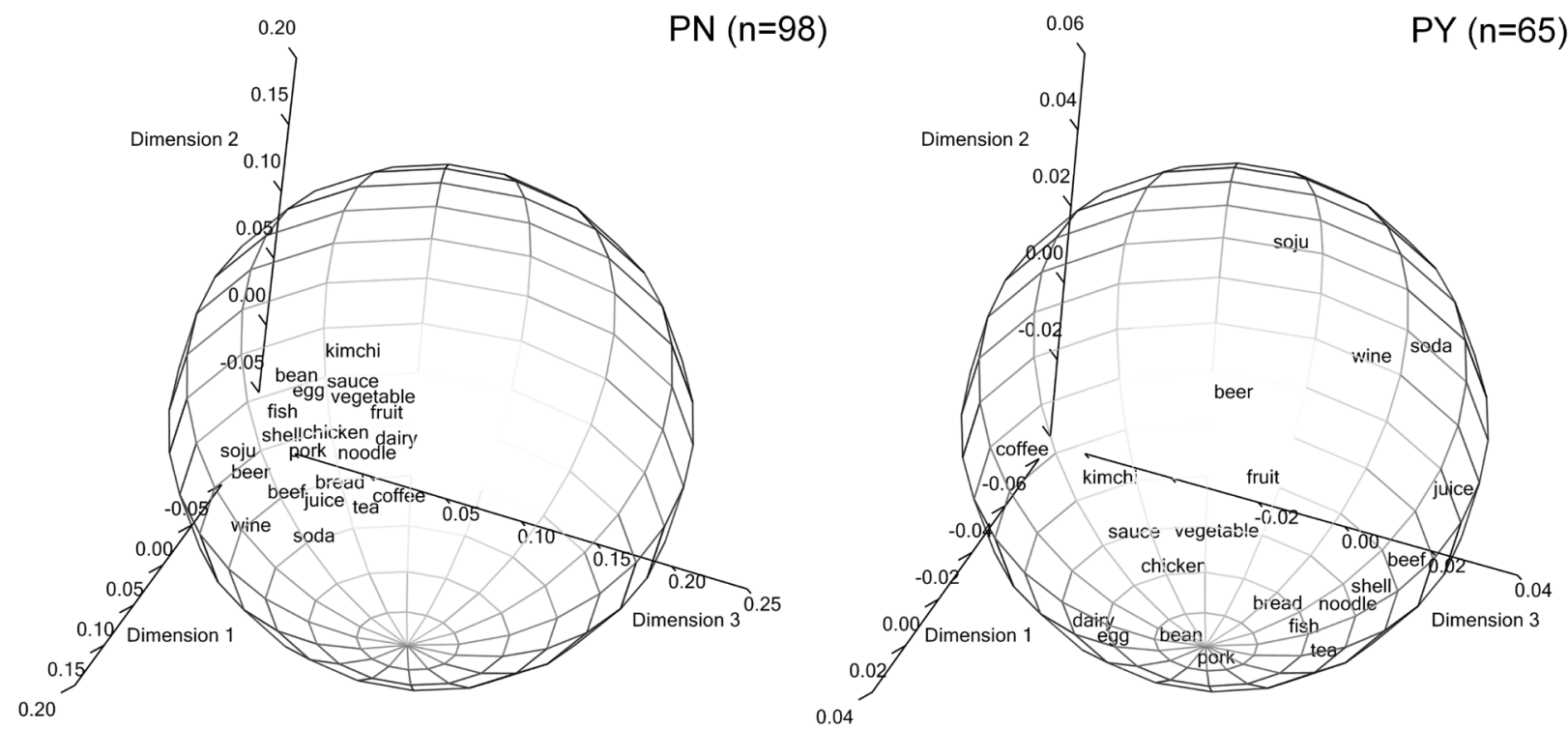

(b)

Figure 22. MDS positional plots of food acceptance (a) and food consumption (b) for the PN and PY groups.

attenuated in a second or later pregnancy. The influence of EG on food consumption behavior signifies a notable change in the judgment on food during and after pregnancy, and prompts questions about pregnancy in terms of cause and effect in dietary life.

The pregnancy is the growth of a new consciousness system baby_CACP in the existing life regime mom_CACP, or a two-ego system in one physical body baby_CACM in mom_CACM. EG may be a lag phase or a transition state in which the two egos referred to 7-CL or subjects adapt and compromise on their different needs for the food. In this regard, virtual food (Chun, 2003) con- 
structed in the background of the consciousness and different food experiences may potentially serve as references (inference memories stored in either 6-CL or 8-CL) in the judgment of food for consumption (see Figure 15).

It may be considered that two subjects communicate with each other in reaching a compromise. As this work is at too early a phase to consider neural signaling, serious consideration should be given to wireless communication via the consciousness channel. In this way, a certain layer of consciousness such as 8-CL, as a top mind level, may have a role as a communication partnered with an inter-subjects regime, CACP family. Although, it is results of from a small sample group and a particular food, it strongly suggests that consciousness approaches is promising new study area for psychologists to reach out.

\section{Discussion}

A decade ago, author carried out research projects of food taste subject and its relation to food choice, and realized difficulties arisen from the mind states of consumer which is fundamentally inaccessible area for food scientists. Particularly, food taste is closely associated with subjective experience cumulated during one's life course including genetic factor. As long as mind state concerned, it is matter of psychology, and if then, can psychologists resolve the food problems such as sweet and sour which are closely related to material science? Which area will be appropriate between food science and psychology to access the problematic mind state? After long speculation on this matter, author reached a conclusion that food scientists is better qualified to deal the problem because food scientist and psychologist are equally living with mind and no difference in pursuing the true nature of mind.

Although psychology covers various mind states and associated human behaviors, these are a part of resultants of mind reaction taken place at the surface of mind but not from the mind itself. In contrast, food scientists know well about methodology with which systematic approach from sensible search for insensible inferences are possible and they know how to use hypothetical modeling, simulation, data processing and establishment of relevant rule or theory in terms of the cause-and-effect approach. As mentioned, there are many findings and supporting theory in pure and applied sciences for food scientists to grasp the mind world.

First thing is to understand the terminologies used in the mind world because there is no clear classification of mind, and thus mind states are understood so confusing with complexity of knowledge, awareness, consciousness, unconsciousness, mind and spirit. Accordingly, author tried to unify these terms with a single consciousness spectrum in such scientific way as wave length.

The CM theory is explainable self, life cycle, subjective experiences, and various mind states using new terminologies such as $\mathrm{CM}, \mathrm{CF}, \mathrm{CA}, \mathrm{CAC}, \mathrm{CACM}$, $\mathrm{CACP}$ and others. Application of Vasubandhu's theory dividing the mind into a multilayered structure of consciousness leads to arguments about the divided mind as based on irrationality (Tuske, 1999) and about tastes sensed by the ton- 
gue as derived not from 5-CL but rather from a system-wide process yielding a decision. Author supports the latter account but the division into several subsystems aids in understanding how the system works as a whole. In this context, the validity of the proposed path model (Chun et al., 2011), constructed by combining subjective (non-food memories) and objective factors (food-related memories), was investigated with respect to routes based on the hypothesis that causal routes represent a main routine of the 'software' governing this path. It was hypothesized that this path was triggered by unconscious factors, but that the effective route was regulated consciously. The role of cause and effect reactions to shaping expectations and rewards entails that memories of historical experiences will serve as important references for decision-making (Wansink, 2003).

In the application of CM-theory, consciousness processing was demonstrated with food acceptance processing model along with feedback control logic in 5-CL level for supplying acquired data onto upper layers where processing time units are different, and thus arbitrary time units are applied. This implies that future, present, and past are integrated into the path (Raftopoulos, 2001) via conscious and unconscious processes (Dehaene \& Naccache, 2001).

Among the consciousness layer, the rating of their importance is hard to define, because every layer has a given roles, however, 7-CL as an egocentric decision-maker judging Virtual food in stored 8-CL, plays is the central role in the processing.

Author like to address that the relationship between objective and subjective experiences is understood as the case of particular and general solutions encountered in the solution of differential equation because the former is valid only in a given boundary condition Therefore, factors affecting the taste of food tremendously increase the complexity that renders the experience of taste inaccessible to methods that confine "knowledge" to continuously accumulating files of data. In short, the increasing experimental data are of little help when attempting to access the nature of the taste of food. The ultimate goal of a consciousness-oriented approach is not to add variables to those that have already been established as contributing to the evaluation of the taste of food, but rather to condense these factors into a fundamental mental framework that accounts for the emergence of particular tastes.

The mCML approaches to seem to suggest the existence of a divided mind based in irrationality (Tuske, 1999). However, the division into several subsystems aids in understanding how the system works as a whole. Categorizing food and behavioral issues into relevant layers leaves ample room for adjusting the boundaries of categories given the ambiguity in terminology and definitions (e.g., "schema in 6-CL", "cooking experience in 7-CL", etc.).

The sense of taste with respect to food is of particular importance in terms of the processes by which sensory experiences link the external world to the world of the mind. Indeed, sensing via the tongue is not momentary; this experience lasts several hours and is perceived at varying levels of intensity that operates 
unconsciously (Haynes \& Rees, 2006).

These factors influence appetite, satiation, and satisfaction in dynamic ways that differ among individuals with different judgment criteria; these criteria are not adequately explained in conventional ways of reference to concepts of consciousness.

The influence of EG on food consumption signals a notable change in judgments about food during and after pregnancy, and begs questions about the cause and effect of pregnancy with regard to dietary habits. First, what is the nature of pregnancy from the perspective of consciousness? Is it the growth of a new consciousness system within an existing life, a configuration of two selves, or the establishment of a two-ego system in one physical body? Second, what does EG mean? It might represent a phase involving self-discipline or a transitional state in which the two egos refer to 7-CL to adopt a new dual system whereby compromise between the different needs for food emanating from the two selves is achieved. In this context, virtual food (Chun, 2003), constructed in the background of consciousness and from memories stored in either 7-CL or 8-CL, as well as different food experiences might serve as references for the judgments underlying food consumption. Third, does it possible for the two subjects to communicate with each other in order to reach a compromise, thus avoiding critical damage to both selves using a mechanism resemble a hotline that spans dual neural networks? Because the neural networking of the fetus is not sufficiently developed to consider the operation of neural signaling, should serious consideration be given to a form of wireless communication via the consciousness channel? In this way, 8-CL, the highest level, might play a role as a communications tower in the inter-subjective realm of 7-CL and 8-CL.

Considering the remarkable effect of EG on dietary behavior, and on food consumption during pregnancy in particular, the changes in consciousness should be considered to be variables in the food acceptance process. Thus, the experience of pregnancy may occupy an important position in a woman's reference memory, influencing dietary behaviors such as food preferences and satisfaction. This strongly suggests that the content and factors of the food evaluation process can differentiate between women who have been pregnant and those who have not. Thus, we believe that the latent consciousness layer governing the sensorial organ is activated during pregnancy to navigate forward mutual benefit of two.

The CM theory can be applied to other fields, and one of them is the musical expression of food taste. Kim et al. (2005) demonstrated methodology how musical score of potato chip can be constructed from the cognitive sensory barcode when time units of the relevant CML (see Figure 17) are set.in the mCML processing pathway. This suggests that food taste can be presented by other ways aside the current sensory method.

\section{References}

Anacker, S. (1984). Seven Works of Vasubandhu. Delhi: Motilal Banarsidass. 
Bargh, J. A., Chaiken, S., Raymond, P., \& Hymes, C. (1996). The Automatic Evaluation Effect: Unconditional Automatic Attitude Activation with a Pronunciation Task. Journal of Experimental Social Psychology, 32, 104-128.

https://doi.org/10.1006/jesp.1996.0005

Bergstrom, L. (2000). Non-Baryonic Dark Matter: Observational Evidence and Detection Methods. Reports on Progress in Physics, 63, 793-841.

https://doi.org/10.1088/0034-4885/63/5/2r3

Berthoud, H. R., Lenard, N. R., \& Shin, A. C. (2011). Food Reward, Hyperphagia, and Obesity. American Journal of Physiology - Regulatory, Integrative and Comparative Physiology, 300, R1266-R1277. https://doi.org/10.1152/ajpregu.00028.2011

Bertone, G., Hooper, D., \& Silk, J. (2005). Particle Dark Matter: Evidence, Candidates and Constraints. Physics Reports, 405, 279-390. https://doi.org/10.1016/j.physrep.2004.08.031

Booth, D. A. (2008). Physiological Regulation through Learnt Control of Appetites by Contingencies among Signals from External and Internal Environments. Appetite, 51, 433. https://doi.org/10.1016/j.appet.2008.06.008

Booth, D. A., Konle, M., \& Sharpe, O. (2008). Taste of Savoury Foods Does Not Need a Fifth Receptor Type. Appetite, 51, 355. https://doi.org/10.1016/j.appet.2008.04.042

Bowen, D. J. (1992). Taste and Food Preference Changes across the Course of Pregnancy. Appetite, 19, 233-242. https://doi.org/10.1016/0195-6663(92)90164-2

Bredahl, L., \& Grunert, K. G. (1997). Food-Related Lifestyle Trends in Germany 1993-1996. MAPP Working Paper, April 1997. Aarhus: The Aarhus School of Business.

Bruns, K., \& Grunert, K. G. (1995). Development and Testing of a Cross-Culturally Valid Instrument: Food-Related Life Style. Advances in Consumer Research, 22, 475-480.

Cho, W. I., \& Chun, J. K. (2012). Cognitive Sensory Evaluation of Food Acceptance Based on Hierarchical Structure of Multilayer Consciousness. 5th European Conference on Sensory and Consumer Research, Bern, 9-12 September 2012.

Chun, J. K. (2000). Concept of Food Sensory Engineering as Function of Time. Annual Meeting of the Korean Society for Industrial Food Engineering, Seoul.

Chun, J. K. (2001). Oriental Concept of Hidden Layers in Neural Network Control and Its Application to Food Sensory Control. 11th World Congress of Food Science and Technology, Seoul.

Chun, J. K. (2002). Concept of Food Sensory Engineering and Its Application to Sensory Evaluation. Food Engineering Progress, 6, 288-299.

Chun, J. K. (2003). New Approach on Obesity Problem Using Virtual Food. Food Engineering Progress, 7, 44-53.

Chun, J. K., \& Cho, W. I. (2011). Consciousness-Oriented Approach to Food Taste. In E. J. Lynch, and A. P. Petrov (Eds.), The Sense of Taste, New York: NOVA Science Publishers Inc.

Chun, J. K., Lim, S. W., \& Cho, W. I. (2011). Effect of Pregnancy and Consciousness Factors on Food Related Behavior, Chapter 128. In Preedy et al. (Eds.), Handbook of Behavior, Diet, and Nutrition. New York: Springer.

Copi, C. J., Schramm, D. N., \& Turner, M. S. (1995). Big-Bang Nucleosynthesis and the Baryon Density of the Universe. Science, 267, 192-199.

https://doi.org/10.1126/science.7809624

Crick, F., Barnett, L, Brenner, S., \& Watts-Tobin, R. J. (1961). General Nature of the Genetic Code for Proteins. Nature, 192, 1227-1232. https://doi.org/10.1038/1921227a0

Damasio, A. (1999). The Feeling of What Happens: Body, Emotion and the Making of 
Consciousness. London: Vintage.

Dehaene, S., \& Naccache, L. (2001). Towards a Cognitive Neuroscience of Consciousness: Basic Evidence and a Workspace Framework. Cognition, 79, 1-37. https://doi.org/10.1016/S0010-0277(00)00123-2

Dennette, D. (1991). Consciousness Explained. Boston: Little \& Company.

Dy Jr., M. B. (2001). Philosophy of Man: Selected Readings (p. 97). Goodwill Trading Co.

Edelman, G. (1992). Bright Air, Brilliant Fire: On the Matter of the Mind. New York: Basic Books.

Eilam, E., \& Chikofski, E. J. (2007). Reversing: Secrets of Reverse Engineering (p. 3). Hoboken: John Wiley \& Sons.

Ennis D. M. (1998). Foundations of Sensory Science and a Vision for the Future. Food Technology, 52, 78.

Epstein, S. (1994). Integration of the Cognitive and the Psychodynamic Unconscious. The American psychologist, 49, 709-24. https://doi.org/10.1037/0003-066X.49.8.709

Fazio, R. H., Sanbonmatsu, D. M., Powell, M. C., \& Karades, F. R. (1986). On the Automatic Activation of Attitudes. Journal of Personality and Social Psychology, 50, 229238. https://doi.org/10.1037/0022-3514.50.2.229

Ferrarelli, F., Peterson, M. J., Sarasso, S., Riedner, B. A., Murphy, M. J., Benca, R. M., Bria, P., Kalin, N. H., \& Tononi, G. (2010). Thalamic Dysfunction in Schizophrenia Suggested by Whole-Night Deficits in Slow and Fast Spindles. American Journal of Psychiatry, 167, 1339-1348. https://doi.org/10.1176/appi.ajp.2010.09121731

Gasiorowicz, S. (1974). Quantum Physics. Hoboken: Wiley.

Goswami, A., Read, R., \& Gosowami, M. (1993). The Self-Aware Universe: How Consciousness Creates the Material World. Putnam: New York.

Grunert, K. G., \& Grunert, S. C. (1995). Measuring Subjective Meaning Structures by the Laddering Method: Theoretical Considerations and Methodological Problems. International Journal of Research in Marketing, 12, 209-225.

https://doi.org/10.1016/0167-8116(95)00022-T

Gutman, J. (1982). A Means-End Chain Model Based on Consumer Categorization Processes. The Journal of Marketing, 46, 60-72. https://doi.org/10.2307/3203341

Hawkins, J., \& Sandra, B. (2005). On Intelligence: Times Books. NY: Henry Holt and Co.

Haynes, J. D., \& Rees, G. (2006). Decoding Mental States from Brain Activity in Humans. Nature Reviews, Neuroscience, 7, 523-534. https://doi.org/10.1038/nrn1931

Heisenberg, W. (1927). Über den anschaulichen Inhalt der quantentheoretischen Kinematik und Mechanik. Zeitschrift für Physik, 43, 172-198.

https://doi.org/10.1007/BF01397280

Hinshaw, G. F. (2010). What Is the Universe Made of? Universe 101. NASA/GSFC.

Hohwy, J. (2009). The Neural Correlates of Consciousness: New Experimental Approaches Needed? Consciousness and Cognition, 18, 428-438.

https://doi.org/10.1016/j.concog.2009.02.006

Jarosik et al. (2010). Seven-Year Wilson Microwave Anisotropy Probe (WMAP). Observations: Sky Maps, Systematic Errors, and Basic Results. http://nasa.gov

Jin, J. H., \& Chun, J. K. (2004). Characterization of Consumer Groups Using Cognitive Sensory Evaluation Method Based on Multi-Layer Consciousness. MS Thesis, Seoul: Seoul National University.

Keown, D. (2003). A Dictionary of Buddhism. NY: Oxford University Press.

Kiefer, M., \& Brendel, D. (2006). Attentional Modulation of Unconscious Automatic 
Processes: Evidence from Event-Related Potentials in a Masked Priming Paradigm. Journal of Cognitive Neuroscience, 18, 184-198.

Kim, S. E., Lim, S. W., \& Chun, J. K. (2005). Development of a Method for the Musical Expression of Cognitive Food Taste. Food Science and Biotechnology, 14, 738-742.

Koch, C. (2004). The Quest for Consciousness: A Neurobiological Approach. Englewood, CO: Roberts \& Company Publishers.

Koch, C., \& Tononi, G. (2008). Can Machines be Conscious? IEEE Spectrum, 45, 55. https://doi.org/10.1109/MSPEC.2008.4531463

Lamme, V. A. F. (2004). Separate Neural Definitions of Visual Consciousness and Visual Attention; a Case for Phenomenal Awareness. Neural Networks, 17, 861-872. https://doi.org/10.1016/j.neunet.2004.02.005

Lim, S. W. (2005). Analysis of Cognitive Food Taste as Influenced by Consciousness Layer. Ph.D. Thesis, Seoul: Seoul National University.

Lim, S. W., Chun, J. K., \& Cho, W. I. (2008). Effect of Pregnancy on Food Consumption and Consciousness Factors Associated with Food Satisfaction. Appetite, 50, 519-528. https://doi.org/10.1016/j.appet.2007.10.010

Lodish, H., Berk, A., Ziprusky, S. L., Matsudaira, P., Baltimore, D., \& Daenell, J. (2000). Chapter 21. Nerve Cell. In Lodish, Molecular Cell Biology (4th ed.). New York: Freeman and Company.

Malcolm, N. (1965). Descartes's Proof That His Essence Is Thinking. Philosophical Review, 74, 315-338. https://doi.org/10.2307/2183357

Massimini, M., Ferrarelli, F., Huber, R., Esser, S. K., Singh, H., \& Tononi, G. (2005). Breakdown of Cortical Effective Connectivity during Sleep. Science, 309, 2228-2232.

Meilgaard, M., Civille, G. V., \& Carr, B. T. (2006). Sensory Evaluation Techniques. Boca Raton, FL: CRC Press. https://doi.org/10.1201/b16452

Olson, J., \& Reynolds, T. (1983). Understanding Consumers' Cognitive Structures: Implications for Advertising Strategy. In L. Percy, \& A. Woodside (Eds.), Advertising and Consumer Psychology. Lexington, MA: Lexington Books.

Owen, A. M., Colman, M. R., Boly, M., Davisi, M. H., Laureys, N. S., \& Pickard, J. D. (2006). Detecting Awareness in the Vegetative State. Science, 313, 1402. https://doi.org/10.1126/science.1130197

Pais, A. (1991). Niels Bohr's Times. In Physics, Philosophy and Polity. Oxford: Clarendon Press.

Paradiso, M. A. (2002). Perceptual and Neuronal Correspondence in Primary Visual Cortex. Cognitive Neuroscience/Current Opinion, Neurobiology, 12, 155-161. https://doi.org/10.1016/S0959-4388(02)00311-2

Peebles, P. J. E., \& Ratra, B. T. (2003). The Cosmological Constant and Dark Energy. Reviews of Modern Physics, 75, 559-606. https://doi.org/10.1103/RevModPhys.75.559

Raftopoulos, A. (2001). Is Perception Informationally Encapsulated? The Issue of the Theory-Ladenness of Perception. Cognitive Science, 25, 423-451. https://doi.org/10.1207/s15516709cog2503_4

Scholderer, J., Brunso, K., Bredahl, L., \& Grunert, K. G. (2004). Cross-Cultural Validity of the Food-Related Lifestyles Instrument (FRL) within Western Europe. Appetite, 42, 197-211. https://doi.org/10.1016/j.appet.2003.11.005

Seipel, K., \& Schmid, V. (2005). Evolution of Striated Muscle: Jellyfish and the Origin of Triploblasty. Developmental Biology, 282, 14-26.

https://doi.org/10.1016/j.ydbio.2005.03.032

Shepherd, G. M. (1994). Neurobiology (p. 3). NY: Oxford University Press. 
Shine, S. W., \& Chun, J. K. (2004). Cognitive Sensory Evaluation of Potato Chips Using Cognitive Sensory Barcode and Frequency Curve Method. Food Engineering Progress, 8, 242-248.

Thurstone, L. L. (1927). A Law of Comparative Judgments. Psychological Review, 34, 273-286. https://doi.org/10.1037/h0070288

Trimble, V. (1987). Existence and Nature of Dark Matter in the Universe. Annual Review of Astronomy and Astrophysics, 25, 425-472. https://doi.org/10.1146/annurev.aa.25.090187.002233

Tuske, J. (1999). Being in Two Minds: The Divided Mind in the Nyāyasūtras. Asian Philosophy: An International Journal of the Philosophical Traditions of the East, 9, 229238. https://doi.org/10.1080/09552369908575501

Wansink, B. (2003). Response to Measuring Consumer Response to Food Products. Sensory Tests That Predict Consumer Acceptance. Food Quality and Preference, 14, 23-26. https://doi.org/10.1016/S0950-3293(02)00035-6

Williams, L. E., Bargh, J. A., Nocera, C. C., \& Gray, J. R. (2009). The Unconscious Regulation of Emotion: Nonconscious Reappraisal Goals Modulate Emotional Reactivity. Emotion (Washington DC), 9, 847-854. https://doi.org/10.1037/a0017745

Wilson, R. A. (1977). Leary's 8-Circuit Model of Consciousness, Cosmic Trigger. http://laetusinpraesens.org/ 


\section{Abbreviations}

3-WBP: Three-way-branching perception

3-WBT: Three-way-branching transfer

C-cohf: Consciousness coherent force

$\mathrm{CA}$ : Consciousness aggregate

CAC: Consciousness aggregate Cluster

CACM: Mass bound CAC

CACP: Potential CAC

CF-dst: Consciousness dust

CF-frag: Consciousness fragment

CF: Consciousness fiber

CL: Consciousness layer

CM: Consciousness mesh

CML: Consciousness mesh layer

Cons: Consciousness

CSB: Cognitive sensory barcode

CSE: Cognitive sensory evaluation

CSET: Cognitive sensory evaluation table

CSQ: Cognitive sensory evaluation questionnaire

sCSQ: Simplified cognitive sensory evaluation questionnaire

Exp_CAC: Experience of CAC

Exp_CACM: Experience of CACM

Exp_CACP: Experiencee of CACP

mCML: Multi layered consciousness mesh

OCSB: Overall cognitive sensory barcode

\section{Scientific Research Publishing}

Submit or recommend next manuscript to SCIRP and we will provide best service for you:

Accepting pre-submission inquiries through Email, Facebook, LinkedIn, Twitter, etc. A wide selection of journals (inclusive of 9 subjects, more than 200 journals)

Providing 24-hour high-quality service

User-friendly online submission system

Fair and swift peer-review system

Efficient typesetting and proofreading procedure

Display of the result of downloads and visits, as well as the number of cited articles

Maximum dissemination of your research work

Submit your manuscript at: http://papersubmission.scirp.org/

Or contact psych@scirp.org 